\title{
Uncertainties Associated with Combining Airborne and Ground-Based Doppler Radar Data
}

\author{
PETER S. RAY \\ Department of Meteorology and Supercomputer Computations Research Institute, Florida State University, Tallahassee, Florida \\ DAVID P. JORGENSEN \\ NOAA/ERL/Weather Research Program, Boulder, Colorado
}

(Manuscript received 15 April 1987, in final form 4 August 1987)

\begin{abstract}
Observations with airborne Doppler radar can expand the area of coverage and extend the time a moving weather system can remain under observation. Also, additional analysis methods are possible with the increase in independent estimates of the wind field that can be provided by an airborne sampling system. However, the advantages of airborne Doppler sensing are constrained by the geometry in which the data are collected, as well as errors introduced by uncertainties in the sampling platform location and orientation. Finally, a longer time required to sample a region than is typical for ground-based radars results in increased uncertainties due to the field's evolution and advection during the sampling interval. Uncertainties related to geometry are examined for flight patterns which are for aircraft alone and for those which also utilize data from one and two groundbased radars. These illustrate the distribution and relative magnitude of uncertainty expected for each type of flight pattern and data analysis method. Both the NOAA P-3, and the NCAR ELDORA scanning methodologies are examined.

To evaluate the different flight patterns, a relative quality index is used. It is defined as the reciprocal of the vertical velocity error variance integrated over the analysis domain. This normalized relative quality index is a mean value over the sampled volume. Flight patterns that utilize a single ground-based radar provide coverage over $\sim$ ten times the area in about one-half the time, and with relative quality about ten times better than that by aircraft alone.

Data collection, particularly aircraft data collection, often involves real-time decision making, and storms frequently are not in an ideal location relative to fixed ground-based radars. The best operational decisions require knowledge of eventual synthesis capabilities and the location of the volume to be interrogated relative to those facilities. These concepts are illustrated in a case example. Airborne Doppler and ground-based radar synthesis results are compared and discussed.
\end{abstract}

\section{Introduction}

There are times when researchers are limited by the use of ground-based Doppler radars, and an airborne Doppler radar would seem to mitigate these limitations. One such limitation is observations over the ocean, mountains, or other areas not easily accessed by ground-based radars. Another limitation of groundbased radars is the area a network can cover. If the likelihood is that the phenomena under study will occur within the radar network, then a ground-based system serves adequately. Airborne Doppler radar may be warranted if the time required for capturing the desired number of events with the available-sized ground radar array is too long, or if the event is likely to move through the network before being adequately observed, or if the phenomenon is of a scale larger than can be

Corresponding author address: Dr. Peter Ray, Department of Meteorology, Florida State University, Tallahassee, FL 32306. observed with the available ground-based radar network. The system's portability also allows for interrogation at closer range, resulting in a higher spatial resolution than is often possible with a ground-based radar.

Jorgensen et al. (1983) gave a description of the NOAA P-3 aircraft and its airborne Doppler radar and presented one analysis technique. The NCAR ELDORA airborne system is discussed in Frush et al. (1986) and Walther et al. (1986). Hildebrand et al. (1983) discussed the applications of airborne Doppler radar, the potential for its use alone and in combination with other ground-based radar systems. Ray et al. (1985) discussed different analysis methods suitable for airborne Doppler radar and some of the limitations of these collection methods. Good agreement was obtained between different analysis methods applied to the same Florida, sea breeze-induced convective storm. Airborne Doppler radar collection was related to dualDoppler analysis from ground-based systems. The nature of the uncertainties in the synthesis of airborne 
Doppler radar data due to geometry was illustráted in terms of the more familiar ground-based dual-Doppler techniques. In a comparison between the overdetermined dual-Doppler and the triple-Doppler approach, the expected distribution of uncertainty in the vertical velocity was computed. This approach showed comparable uncertainty in the middle of the analysis domain, but smaller uncertainty near the flight legs using the direct solution, due to the nearly direct measurement of the particle fall speed.

In a two-part paper, Hildebrand and Mueller (1985) and Mueller and Hildebrand (1985) evaluated the use of airborne radar and compared the results with ground-based radar analysis for both dual-Doppler and triple-Doppler analysis techniques. They found good agreement between airborne-measured winds and fields derived from ground-based Doppler radars. The effect of triple-Doppler measurements was an increase in the down-draft speed when compared to the dual-Doppler method. This was presumably due to the correlation that is introduced by the differencing used in the dualDoppler methodology, but not part of the triple-Doppler analysis. They discussed many of the error sources, limitations and suggestions for future improvements, as well as the potential advantages of the airborne platform. Major limitations with the current P-3 airborne system, as it was used in the Hildebrand and Mueller (1985) study, relate to long sample times, coarse horizontal resolution, low sensitivity, poor terminal velocity estimates, and low elevation angles in the tripleDoppler analysis case. They conclude that there are compensating advantages and disadvantages which are case dependent. Ray and Jorgensen (1986) discussed uncertainties to be expected when using airborne and ground-based radars. Still, there are many instances where the value of airborne radar systems is unquestionable.

This paper expands upon these earlier works in cataloging the expected benefits and limitations of using airborne Doppler radar, either alone, or in combination with one or two ground-based systems. It is not possible to compare all the permutations and combinations of flight paths, error sources, and analysis techniques. It is recognized that each application will have special requirements which will dictate the optimum collection strategy. Examples are illustrative of typical collection scenarios with reasonable parameters, and we will focus on errors related to the geometry of sampling, analysis methodology and the effects of evolution.

\section{Overview}

\section{a. Advantages}

Perhaps the fundamental advantage of airborne Doppler radar is its portability. It is often possible for the aircraft to observe with greater resolution than would be possible from the closest ground-based system. For example, the possibility of collecting data on hurricanes over the ocean has opened completely new areas of investigation (e.g., Jorgensen and Marks, 1984). When used in combination with one or two groundbased radars it is possible to extend the choice of analysis algorithms to the dual-Doppler, overdetermined dual-Doppler (Ray and Sangren, 1983), or either one or two approaches to triple-Doppler analysis. The airborne radar can either be in a position to sample the major component of the particle fall speed, and thereby the vertical velocity, or fly at an altitude to contribute to a more accurate estimate of the horizontal divergence (e.g., near the lower boundary). The wealth of additional in situ and remote sensing instrumentation that can be carried by an airborne-Doppler equipped aircraft can greatly augment the analysis that can be done with the Doppler data.

\section{b. Disadvantages}

The present (X-band) system operates on the NOAA $P-3$ aircraft at a PRF which gives an unambiguous velocity interval of about $\pm 12.9 \mathrm{~m} \mathrm{~s}^{-1}$; this can make unfolding tedious if not difficult. Corrections to all of the aircraft parameters (pitch, roll, etc.) as well as uncertainties in aircraft position add to the analysis burden. The relatively long data collection times are due to a typical aircraft speed of about $140 \mathrm{~m} \mathrm{~s}^{-1}(8.4 \mathrm{~km}$ $\min ^{-1}$ ). It is common for two legs of data to take at least $7 \mathrm{~min}$ to collect and it is not unusual for data collection times to be several minutes or, in the case of hurricane penetrations, even an hour or so longer. This increases the uncertainty due to advection and evolution effects. In principle, it is possible to correct for advection, but only if a reliable estimate of storm motion is available and only to the extent that the storm moves as a unit. There is no remedy for the situation in which the system is undergoing change during the collection interval. As pointed out by Hildebrand and Mueller (1985), the relative position of the aircraft is usually adequately known, but drift in the Inertial Navigation System (INS) position requires that the aircraft position be independently adjusted when airborne Doppler radar data are combined with data from ground-based systems in order to insure that data registration is within $\pm 1 \mathrm{~km}$. Possible methods include matching reflectivity fields, comparison with VOR positions, tracking radar, Global Positioning Satellite System, or cross-link LORAN-C techniques.

\section{Assessment}

Characteristics of the NOAA P-3 airborne Doppler radar are given in Jorgensen et al. (1983) and Hildebrand and Mueller (1985). The radar antenna is mounted in the tail of the aircraft with its rotation about the aircraft flight axis, collecting data roughly normal to flight track and prescribing a helical scan in space. The convention used here is that the elevation angle is the deviation from horizontal, ranging between $\pm 90^{\circ}$. Azimuth is the departure in a clockwise direction from $0^{\circ}$ at north. The antenna rotates once every $7.5 \mathrm{~s}$ 
which corresponds to a spacing of about $1.05 \mathrm{~km}$ along the flight path at typical P-3 true airspeeds.

The $\mathrm{P}-3$ radar processor has an adjustable range to the first gate, but in all the assessments presented here the range samples begin near the radar and extend to $\sim 40 \mathrm{~km}$ with 256 gates spaced $150 \mathrm{~m}$ apart. It is presumed that the ground-based radar extends to a range of $150 \mathrm{~km}$ (PRF of $1000 \mathrm{~s}^{-1}$ ).

For comparison, the coverage area and distribution of uncertainty for a conventional ground-based dualDoppler network is presented in Fig. 1a. The uncertainty becomes unbounded near the radar baseline and is a minimum near where the radar beams intersect orthogonally. A less obvious restriction is that the maximum elevation angle must be small (less than $45^{\circ}$ ). This restriction implies that one would not expect good synthesis at ranges $<20 \mathrm{~km}$ from either radar.

To assess an overall quality factor, Ray and Jorgensen (1986) devised a relative quality index, the $\kappa^{A}$-index, which is defined as $\kappa^{A}=\iint\left(1 / \sigma_{w}^{2}\right) d x d y$ where $\kappa^{A}$ was evaluated at $5 \mathrm{~km}$ height unless otherwise noted. Hence, a relatively large value of $\kappa^{A}$ would be considered a "better" pattern than a low value of $\kappa^{A}$. This is similar to that done by Ray and Sangren (1983). To incorporate a vertical variations, we introduce an analogous three-dimensional relative quality index $\kappa^{V}$ $=\iiint\left(1 / \sigma_{w}{ }^{2}\right) d x d y d z$. The average value in the domains $\kappa_{N}^{A}$ and $\kappa_{N}{ }^{V}$ can be found by dividing $\kappa^{A}$ and $\kappa^{V}$ by the respective area and volume sampled. All computations include data from both sides of the baseline (the line which passes through both ground-based radar locations). For values on one side of the baseline, the tabulated values may be divided by 2 . Methods used to determine $\sigma_{w}{ }^{2}$ are given in the Appendix. The assessment is first done for the NOAA P-3 configuration and next for the ELDORA configuration.

\section{a. Airborne Doppler radar alone}

\section{1) NOAA P-3}

The optimum flight pattern will depend on the location of the storm, the degree that the storm is changing or evolving, the need to sample special regions particularly well, (e.g., low-level divergence), and restrictions of air space. But within these limitations, it is worthwhile to examine the characteristics of different "generic" flight patterns. We have selected the vertical velocity field at $5 \mathrm{~km}$ altitude to illustrate the error distribution in most cases. Two methods of analysis are possible. One is the dual-Doppler method, which may be used in an overdetermined sense as in Ray et al. (1985), and the other is the direct method (or its variations), in which it is possible to compute vertical particle speed directly. The requirements for the first method are that the data come from at least two legs which are nearly orthogonal. For the second analysis method, the data must come from at least three legs, and at least one leg must have an elevation angle that is greater than $45^{\circ}$ in order to view a significant portion of the particle fall speed.

Ray et al. (1985) showed that when using dualDoppler methods, wind field synthesis for a point over a flight leg is analogous to a synthesis near a groundbased dual-Doppler radar baseline. The uncertainties are large. This is illustrated in Fig. 1b for an "L-pattern."

The region with the smallest uncertainty is that part interrogated by the radar when the plane was at the beginning and end of the complete pattern. This area of good synthesis is about the same size and with the same uncertainty as obtained in one lobe of the groundbased dual-Doppler synthesis. This means that from a geometric point of view, the data near the ends of the flight legs and at greatest range will be most accurate. However, any uncertainty related to the time difference between sampling points may serve to mitigate the geometric advantage. It can be seen in Table 1 that the area sampled in this pattern of $40 \mathrm{~km}$ legs is considerably smaller (by a factor of nearly 45) than is sampled by a ground-based dual-Doppler pair. The advantage is, of course, that the legs usually can be positioned near the storm to provide data that may otherwise not be obtained.

To assess the sensitivity of these calculations to the height of the storm top, downward integration was used assuming both a 10 and $14 \mathrm{~km}$ upper boundary, with flight altitudes of both 1.0 and $5.0 \mathrm{~km}$ (typical highest level flown by P-3). The volume sampled showed the predictable small reduction due to the truncation of the sampled cubic region near the boundaries. This reduction is because the legs are $40 \mathrm{~km}$ long and the maximum radar range has been specified also at $40 \mathrm{~km}$.

For flights at $5.0 \mathrm{~km}$ height there is a $20 \%$ improvement in the quality index when the storm top is $10 \mathrm{~km}$ instead of $14 \mathrm{~km}$, even though there is nearly 5000 fewer cubic kilometers sampled. This improvement is due to smaller maximum elevation angles that are required and therefore the average uncertainty $\left(\mathrm{m}^{2} \mathrm{~s}^{-2}\right)$ was $40 \%$ smaller. For a flight altitude of $1.0 \mathrm{~km}$, essentially the same results were found.

It might be expected that it would be best, from a dual-leg aircraft synthesis point of view, to interrogate storms near the altitude corresponding to half their height so as to minimize the maximum elevation angle. The tests in Table 1 confirm this. For the 10 and 14 $\mathrm{km}$ tall sample volumes, there is a $32 \%$ and a $37 \%$ increase in the pattern quality, respectively, when the flight level is increased from 1 to $5 \mathrm{~km}$. However, there may be circumstances which would justify flying at an altitude different from the altitude near the middle level of the storm. Such reasons could include the need for a more accurate estimate of the low-level divergence.

Results are now presented for flight patterns of nonorthogonal intersecting legs. The angle of intersection between the legs is varied from $\Theta=45^{\circ}$ to $135^{\circ}$ in $15^{\circ}$ 

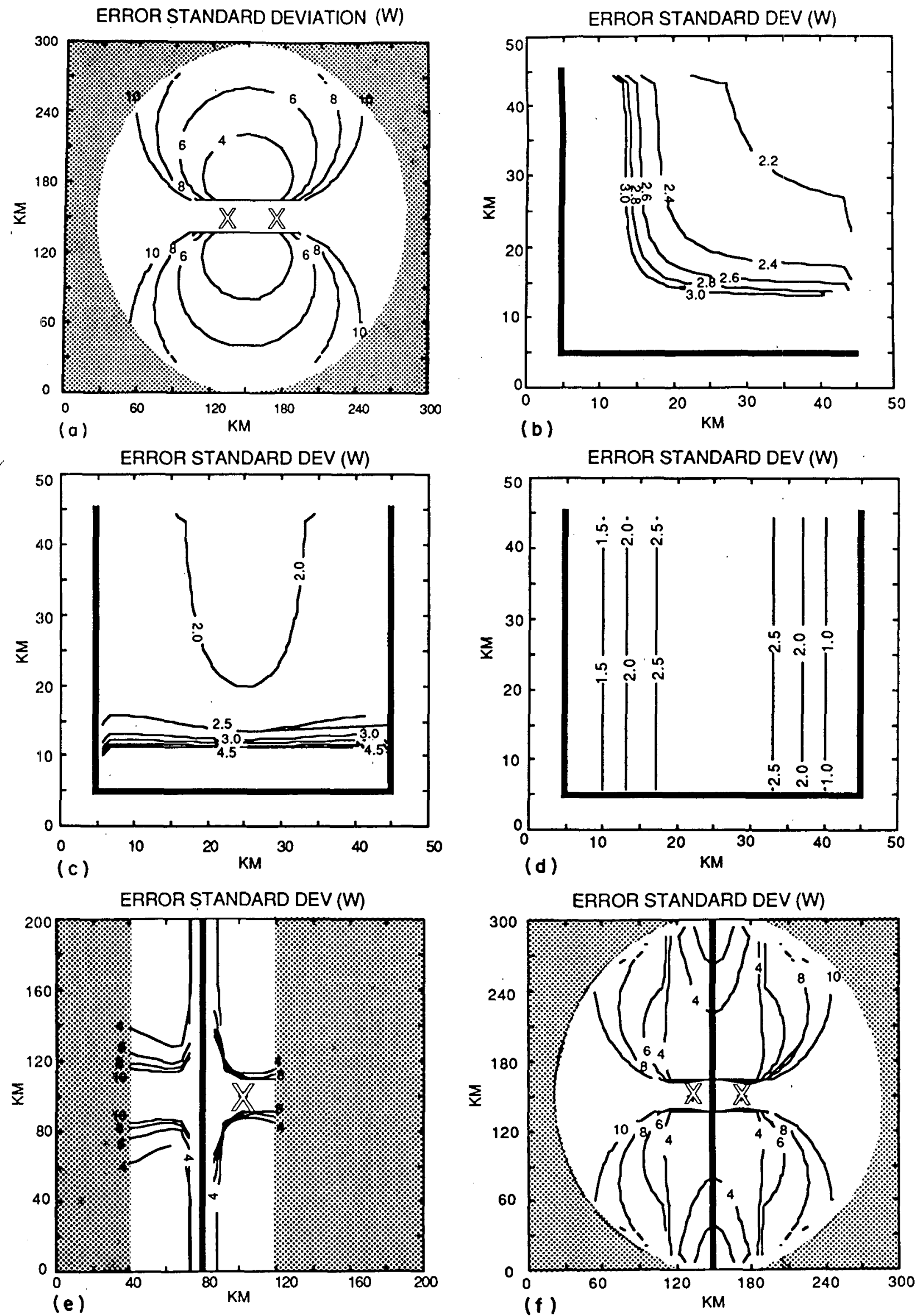


\section{ERROR STANDARD DEVIATION (W)}
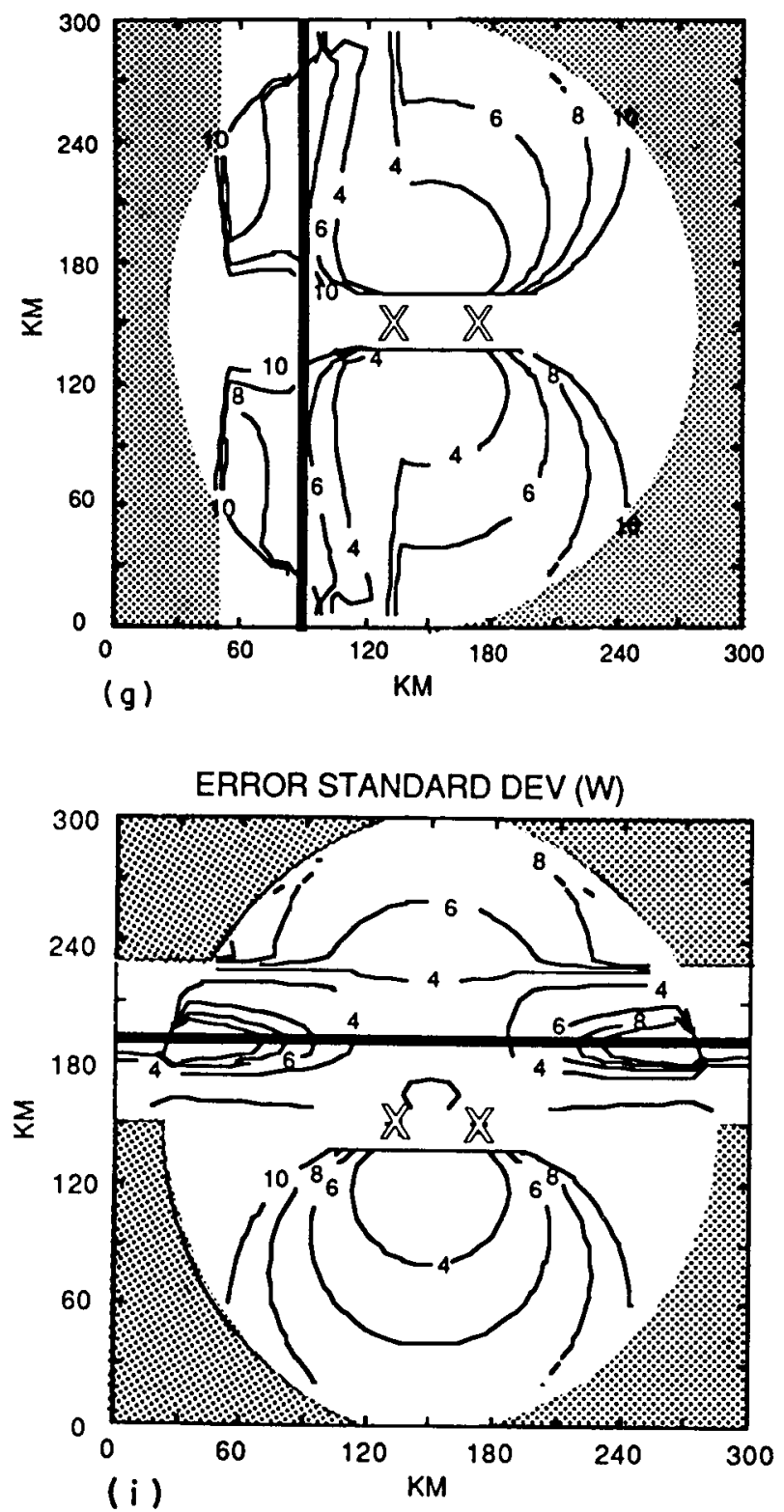

increments. The results from these "V-shaped" patterns are presented in Table 1 and Fig. 2. The domain top is set at $14 \mathrm{~km}$ and the flight level specified at $5 \mathrm{~km}$. For intersection angles greater than $90^{\circ}$, the common viewing area is restricted to a wedge between the leg. This wedge becomes narrower $\left(180^{\circ}-\Theta\right)$ as the between-leg angle increases, and thus the sampled volume correspondingly decreases.

The pattern quality rapidly rises as the between-leg angle approaches $90^{\circ}$ and then more slowly decreases to the value at $120^{\circ}$, where it rapidly declines due to a similar decrease in sampling volume. The index at $90^{\circ}$ is $44 \%$ higher than the value for a $75^{\circ}$ intersection

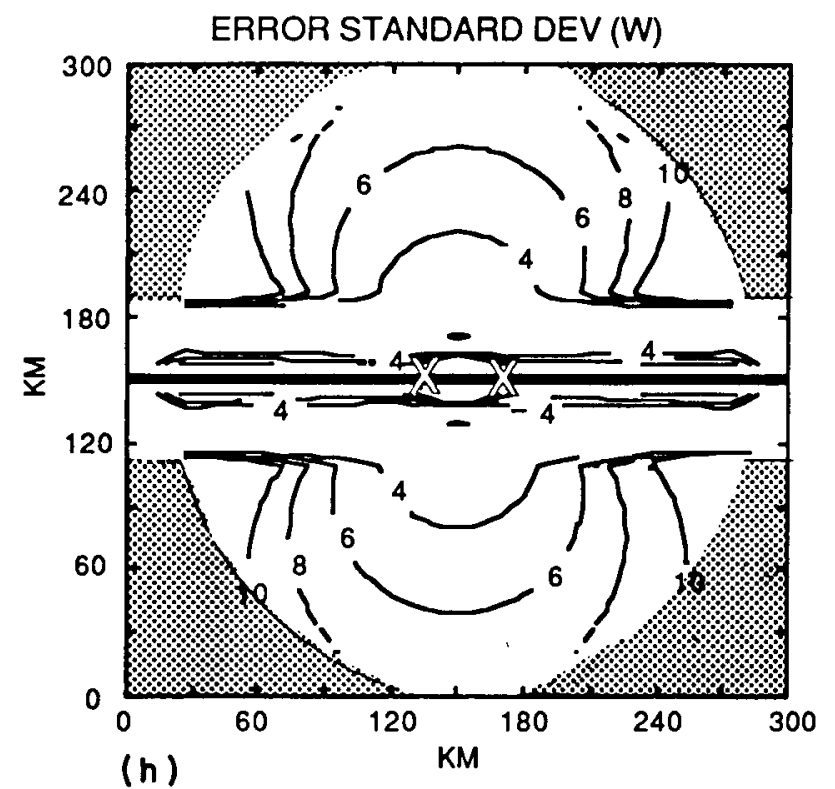

FIG. 1. Errors are expressed as standard deviations and have units of $\mathrm{m} \mathrm{s}^{-1}$. Aircraft flight altitude is assumed to be $5 \mathrm{~km}$ and storms are considered to have tops at $10 \mathrm{~km}$. Where used, downward integration is assumed. Ground-based radar locations are indicated by " $X$ " and flight paths by a heavy line. Stippling indicates area beyond the range of at least two radars. (a) Conventional ground-based DualDoppler rms error in vertical velocity at $5 \mathrm{~km}$ altitude. Radars are separated by $40 \mathrm{~km}$. Errors are given for an "L pattern" by aircraft in (b) and, for the "U pattern" in (c). In (d), the "U" pattern is flown using the direct method of solution. Note that in (c) and (d) the height of synthesis is $\mathbf{0 ~} \mathrm{km}$. The error pattern with flights in coordination with a single radar is shown for a flight which comes to within $20 \mathrm{~km}$ of the radar's location (e). The pattern bisecting the baseline of two ground-based radars is given in ( $f$ ) and perpendicular to the baseline and displaced $20 \mathrm{~km}$ from the closed radar in (g). Uncertainties from a flight path parallel to baseline and through the radar locations is shown in (h) and for a flight pattern parallel to the baseline but displaced $40 \mathrm{~km}$ in (i).

but only $2 \%$ larger than that for a $105^{\circ}$ intersection. Since the volume sampled by the $105^{\circ}$ intersection case is smaller, the average index is actually larger $(10 \%)$ than the average value for the $90^{\circ}$ case. The case of a between-leg angle of $60^{\circ}$ is instructive to examine since it is this angle represented in two legs of an equilateral triangle circumscribing a region of interest. The quality index for the right-angle pattern is $150 \%$ greater than that for the pattern with legs intersecting at $60^{\circ}$.

It might seem that the best data would be collected in the region embraced by the legs. In fact, as mentioned in Ray et al. (1985), this is not true for patterns with between-leg intersection angles much less than 
TABLE 1. Sensitivity of airborne Doppler rádar uncertainty to between-leg angle and storm height.

\begin{tabular}{cccccr}
\hline $\begin{array}{c}\text { Angle } \\
\text { between legs } \\
\text { (degrees) }\end{array}$ & $\begin{array}{c}\text { Storm } \\
\text { top } \\
(\mathrm{km})\end{array}$ & $\begin{array}{c}\text { Flight } \\
\text { level } \\
(\mathrm{km})\end{array}$ & $\begin{array}{c}\kappa^{V} \\
\left(10^{-12} \mathrm{~s}^{-2}\right)\end{array}$ & $\begin{array}{c}\kappa_{N}{ }^{V} \\
\left(10^{-12} \mathrm{~s}^{-2}\right)\end{array}$ & $\begin{array}{r}\text { Volume } \\
\left(\mathrm{km}^{3}\right)\end{array}$ \\
\hline 45 & 14 & 5 & 1925 & 0.1081 & 17805 \\
$45^{*}$ & 14 & 5 & 55 & 0.0059 & 9279 \\
60 & 14 & 5 & 1964 & 0.1131 & 17365 \\
$60^{*}$ & 14 & 5 & 772 & 0.0558 & 12933 \\
75 & 14 & 5 & 2727 & 0.1589 & 17169 \\
$75^{*}$ & 14 & 5 & 2521 & 0.1467 & 17188 \\
90 & 14 & 5 & 4904 & 0.2583 & 18983 \\
90 & 14 & 1 & 3099 & 0.1716 & 18062 \\
90 & 10 & 5 & 6026 & 0.4266 & 14126 \\
90 & 10 & 1 & 4105 & 0.2958 & 13877 \\
105 & 14 & 5 & 4800 & 0.2866 & 16749 \\
120 & 14 & 5 & 3425 & 0.2665 & 12850 \\
135 & 14 & 5 & 1750 & 0.1909 & 9166 \\
\hline
\end{tabular}

* Includes only the volume between a vertical extension of the flight legs.

$90^{\circ}$. This is because as the angle becomes more acute, the geometric perspective increasingly resembles the analogue of being close to a dual-Doppler radar baseline with the between-beam angle becoming very large $\left(180^{\circ}-\theta\right)$. Also, the distance between the plane's location on each leg when viewing a common point also decreases as the angle between legs becomes more acute. This has the effect of drawing the radars closer together. The most accurate data are collected in the region external to the area between the legs. Here the between-beam angle is equal to between-leg angle and the range to the point of interest can be longer, thus decreasing the maximum elevation angle used in the synthesis.

A simple notion might be to capture the area of interest between a pair of adjacent legs. It can be shown that for acute between-leg angles the total volume observed from both radars decreases only slowly as the angle becomes smaller, but that the wedge of common data acquisition for obtuse between-leg angles rapidly declines with increasing angle. The between-leg volume rapidly decreases with decreasing angle between the legs and the slow decline observed in the total volume observed comes largely from the area outside that enclosed by the flight legs. Perhaps more importantly, the two locations of the aircraft when observing a common point become closer as the between-leg angle decreases.

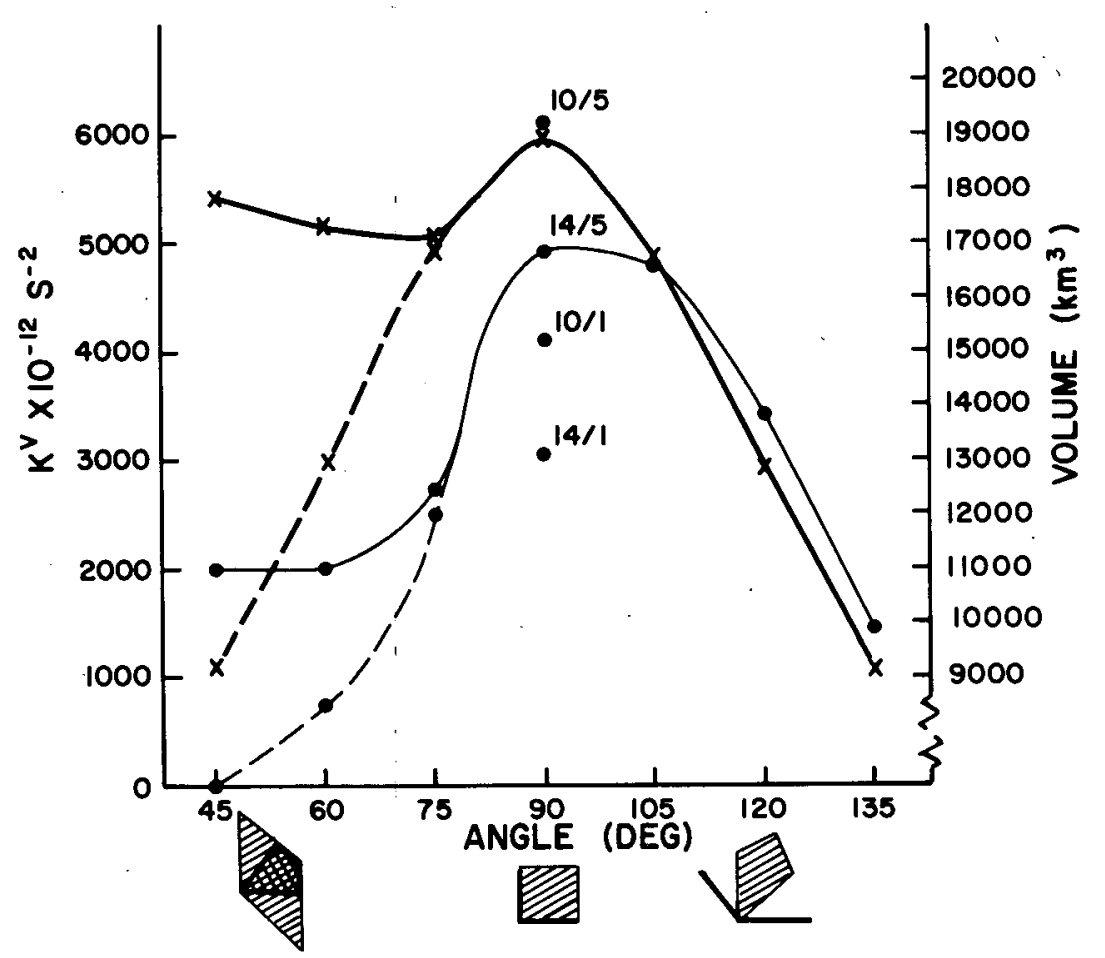

FIG. 2. Distribution of certainty index (thin line) and volume sampled (thick line) for two flight legs separated by angle $\theta$. A smooth curve has been drawn through the angles used in the computation. These points are indicated by circles and crosses. The drawings across the bottom indicate the common area covered by the radar on both flight legs. The dashed line represents values when only the area between the flight legs is considered. This is applicable for the condition $\Theta<90^{\circ}$. The column of points for $\Theta=90^{\circ}$ is for different storm heights and flight levels. The notation is storm top/flight level, both in kilometers. 
The angle formed by the beams is $\left(180^{\circ}-\Theta\right)$ and the geometric analog rapidly approaches the "baseline" problem in the case of ground-based radars. This is seen in the table entry $\kappa_{N}{ }^{V}$ which is $30 \%$ less than the perpendicular leg $90^{\circ}$ for a between-leg angle of $75^{\circ}$, and $66 \%$ less for an angle of $60^{\circ}$. Thus, even though the coverage may be satisfactory in the close vicinity of a storm with an acute angle between legs, the error magnification in the synthesis is large.

These relationships are portrayed in Fig. 2. Here we see that there is a rather rapid increase in the quality index to a maximum at $0=90^{\circ}$ and a somewhat more gradual decrease after that. A broad maximum exists between $90^{\circ}-105^{\circ}$. For a given angle increment greater than $90^{\circ}$ the quality index has a larger value than for the same increment less than $90^{\circ}$. If only the volume between the legs is considered, the quality index is much reduced for flight-leg intersection angles $<75^{\circ}$. This is because much of the contribution to the quality index comes from the volume outside the flight legs when the angle formed by the intersection of those legs is acute.

Similarly, the volume sampled is a maximum when the intersection angle is $90^{\circ}$, but the total volume is not much reduced for acute intersection angles when the volume outside the flight legs is also considered. When the volume is restricted to only that portion within the flight legs, the decrease in volume with angle is nearly symmetric about the $90^{\circ} \mathrm{L}$ pattern.

The sensitivity to the sampling altitude and maximum height of the sampling volume is assessed next. In Fig. 2, for the case of the right angle flight track, the ${ }^{V} V$ index was computed for combinations of two different sampling volume heights and simulated aircraft altitudes. Even though the total volume is greater for the $14 \mathrm{~km}$ depth than the $10 \mathrm{~km}$ depth, the ${ }^{V}$ is smaller. This is because the shallower volume requires smaller maximum elevation angles. This results in more accurate estimates of divergence, and therefore, vertical velocity. A volume of fewer, but more accurate vertical velocities, yields a greater $\kappa^{V}$. This means that, overall, one would expect to compute more accurate vertical velocities for small storms than for the deepest storms. For both volumes, $\kappa^{V}$ was greater when the simulated aircraft was nearer midlevel. This is because the elevation angle extremes are minimized when the aircraft flies at middle levels.

However, if two accurate angle legs are joined by a third leg, forming a triangular flight pattern, the uncertainty is greatly reduced. As shown in Table 2 for two different synthesis methods, the accuracy of recovery is quite good. The important remaining caveat is that of the increased errors resulting from the long data acquisition time required. This case is discussed further below.

When triple-Doppler methods are used, as illustrated in Fig. 1d, the uncertainties are small near the parallel flight legs since the beams from the different legs intersect nearly orthogonally (producing nearly independent samples of each wind component). Since the flight altitude is set at $5 \mathrm{~km}$ and the errors in $w$ are unbounded at this height from the direct method, the uncertainty at $0 \mathrm{~km}$ (or equivalently, $10 \mathrm{~km}$ height) is illustrated in both Figs. 1c, d. For comparison, the overdetermined dual-Doppler error is shown in Fig. 1c for the same "U-pattern."

Another method of circumscribing a storm is to fly an equilateral triangle pattern around it. It has been shown that the synthesis using just two legs is expected to be less accurate than that done with, for example,

TABLE 2. Reliability of airborne collection schemes.

\begin{tabular}{|c|c|c|c|}
\hline Collector & $\begin{array}{c}\kappa^{V} \text {-Index } \\
\left(\times 10^{-12} s^{2}\right)\end{array}$ & $\begin{array}{c}\kappa_{N}{ }^{V} \text {-Index } \\
\left(\times 10^{-12} \mathrm{~s}^{2}\right)\end{array}$ & $\begin{array}{c}\text { Volume } \\
\left(\mathrm{km}^{\mathbf{3}}\right)\end{array}$ \\
\hline Dual Doppler (ground based) & 47488 & 0.0558 & 850710 \\
\hline Airborne dual-Doppler "L-pattern" & 4904 & 0.2583 & 18903 \\
\hline Airborne dual-Doppler "U-pattern" (0 km) (overdetermined) & 7774 & 0.2583 & 21607 \\
\hline Airborne triple-Doppler "U-pattern" $(0 \mathrm{~km})$ (direct) & 5450 & 0.2573 & 21179 \\
\hline Triangle around $40 \mathrm{~km}$ diameter storm (overdetermined) & 8135 & 0.3768 & 21589 \\
\hline Triangle around $40 \mathrm{~km}$ diameter storm (direct, downward integration) & 10207 & 0.4928 & 20713 \\
\hline \multicolumn{4}{|l|}{ Airborne with one ground-based radar } \\
\hline closest point $0 \mathrm{~km}$ from radar & 80186 & 0.2502 & 320464 \\
\hline closest point $20 \mathrm{~km}$ from radar & 75473 & 0.2393 & 315420 \\
\hline closest point $40 \mathrm{~km}$ from radar & 62862 & 0.2040 & 300636 \\
\hline closest point $60 \mathrm{~km}$ from radar & 46447 & 0.1671 & 277996 \\
\hline \multicolumn{4}{|l|}{ Airborne with two ground based radars } \\
\hline parallel to baseline, $0 \mathrm{~km}$ from baseline & 112398 & 0.1233 & 991582 \\
\hline parallel to baseline, $20 \mathrm{~km}$ from baseline & 119933 & 0.1287 & 932115 \\
\hline parallel to baseline, $40 \mathrm{~km}$ from baseline & 106513 & 0.1151 & 925475 \\
\hline parallel to baseline, $60 \mathrm{~km}$ from baseline & 84994 & 0.0920 & 923852 \\
\hline perpendicular to baseline, $0 \mathrm{~km}$ from bisecting & 82719 & 0.0312 & 864266 \\
\hline perpendicular to baseline, $20 \mathrm{~km}$ from bisecting & 79747 & 0.0919 & 867338 \\
\hline perpendicular to baseline, $40 \mathrm{~km}$ from bisecting & 76362 & 0.0876 & 887890 \\
\hline perpendicular to baseline, $60 \mathrm{~km}$ from bisecting & 73941 & 0.0828 & 893594 \\
\hline
\end{tabular}


an "L-shaped" pattern. However, we might expect that the third leg would contribute additional information and decrease the uncertainty. For example, consider a region of principal interest being a circular cylinder 40 $\mathrm{km}$ in diameter and extending $14 \mathrm{~km}$ in height. This region therefore requires $69.28-\mathrm{km}$ legs and 25 minutes to complete the flight pattern, excluding turns, each requiring about an additional minute. Thus any benefits in reduced errors must be balanced against an increase in data acquisition time. Two methods of analysis are considered (Table 2), the overdetermined dualDoppler method and the direct solution where the uncontaminated-by-particle-fall-speed horizontal wind components are used for integration (downward) to obtain the vertical wind component. The reliability for both analysis techniques is somewhat improved over the "U-pattern" by nearly a factor of 2 for the direct method, but at the expense of over two and one-half times greater acquisition time.

\section{2) THE NCAR ELECTRA}

The proposed NCAR ELDORA scanning strategy calls for the simultaneous collection of data from two antennae, both rotating about the aircraft axis, but with one antenna pointing slightly forward and the other slightly backward. This is schematically illustrated in Fig. 3. Thus, as the aircraft flies in a straight line, a volume is sampled first by the forward-pointing antenna and then by the backward-pointing antenna. If the beam angle is $\phi$ from orthogonal to the flight axis, then the two beams will intersect at $\phi=2 \phi$. For a point located $D \mathrm{~m}$ from the aircraft, and an aircraft speed of $V_{a}$, this means a time between samples of $2 D \tan (\phi) /$ $V_{a}$. For an aircraft speed of $140 \mathrm{~m} \mathrm{~s}^{-1}, \phi=30^{\circ}$ and a distance of $40 \mathrm{~km}$ to the point of interest, this means a maximum sampling time difference of $8 \mathrm{~min}$. This is considerably shorter than time to fly a simple Lpattern with only one side-looking beam. Another advantage of the ELDORA system is that "dual-Doppler" data can be simultaneously collected on both sides of the aircraft. In addition, not having to perform a turn to collect dual-Doppler data can be a major advantage if the convective system is oriented as a long linear feature (squall-line).

The difference in scanning strategy between the NOAA P-3 and the NCAR ELDORA is illustrated in Fig. 3. In this illustration, the sampling area is $80 \times 80$ $\mathrm{km}$ square. The most efficient method for the NOAA $\mathrm{P}-3$ is a series of four legs, two, $40 \mathrm{~km}$ in length and
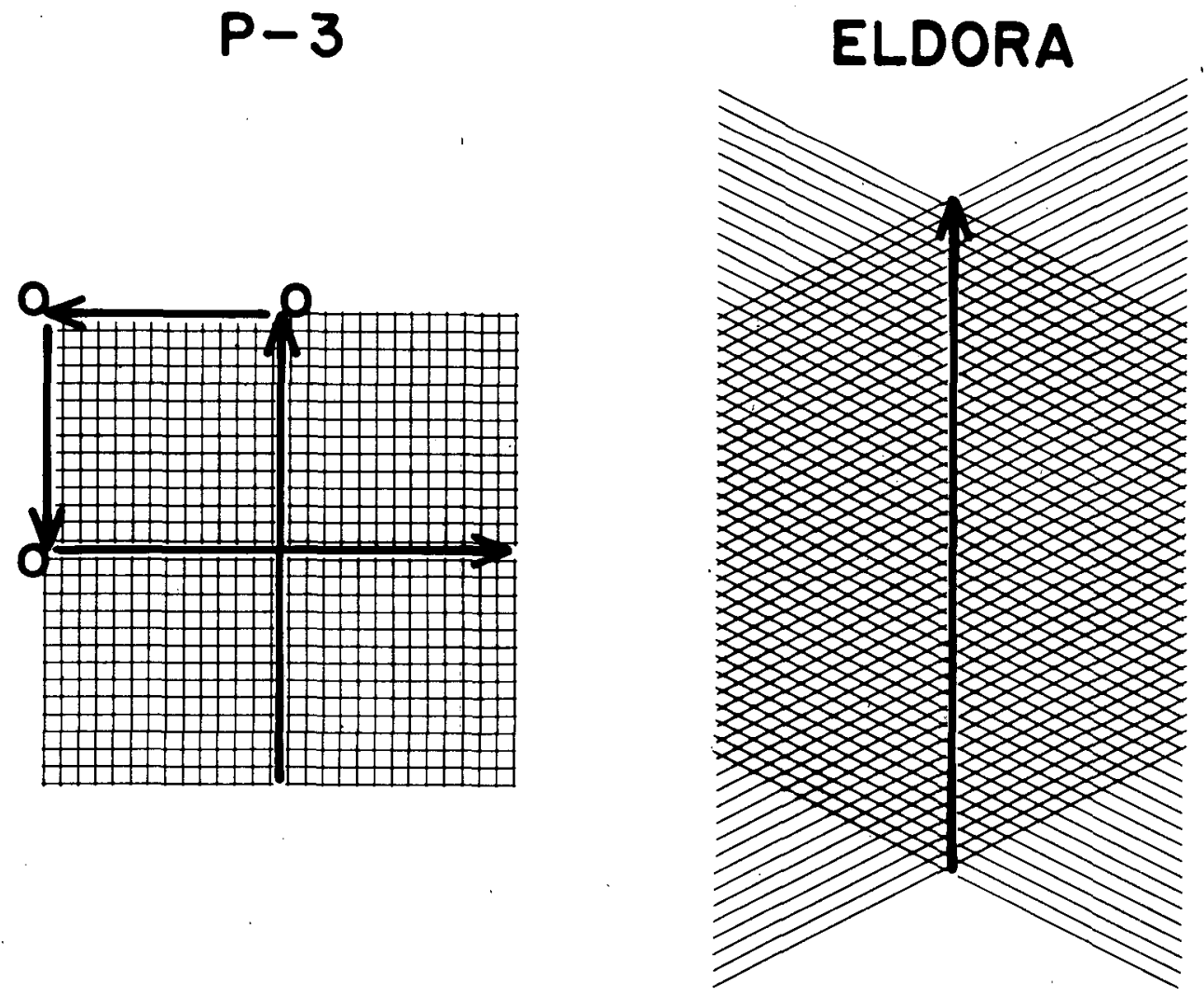

FIG. 3. Sample flight patterns required to cover an $80 \times 80 \mathrm{~km}^{2}$ area with the P-3 side-scanning and the dual-scanning ELDORA radar. The lines represent individual radar beams at flight level. 
two, $80 \mathrm{~km}$ in length. For an aircraft speed of $140 \mathrm{~m}$ $\mathrm{s}^{-1}$, this would take $28.6 \mathrm{~min}$. If three outside turns are included as indicated ( $2 \mathrm{~min}$ each) this increases the sampling time to $34.6 \mathrm{~min}$. For the ELDORA radar, the time is $\{9.5[1+\tan (\phi / 2)]\}$ where $\phi$ is the angle of the intersecting beams. At $\phi=40^{\circ}$ this corresponds to $13 \mathrm{~min}$, and for $\phi=60^{\circ}, 15 \mathrm{~min}$. The sampling time is reduced typically by about $50 \%$.

The effect of different intersecting angles, ranging from $30^{\circ}$ to $70^{\circ}$ are considered. The larger the angle (up to $\phi=90^{\circ}$ ) the smaller the geometric error; but the sampling time is increased by $\left[2 D \tan \left(\phi=90^{\circ}\right)\right] /$ $V_{a}$. The sample volume for all the cases considered was $44800 \mathrm{~km}^{3}$ which only represents one side of the flight track. If both sides are considered, $\kappa^{V}$ should be multiplied by 2.0 . The results are represented in Fig. 4.

There is a linear increase in $\kappa^{V}$ over the range of angles considered. The quality index value for $70^{\circ}$ is close to the maximum for two legs when the angle of intersecting of the flight legs was $90^{\circ}$. The flight time for both patterns is nearly the same, but the distribution is quite different. For the intersecting flight legs mode, the minimum error is in the corner of the box, furthest removed from the flight legs as seen in Fig. 1b. For the ELDORA scan, the error isopleths are parallel to the flight track, with values decreasing with range from the aircraft (see Fig. 5). Minimum values for the ELDORA scan are not as small because the angle of intersection

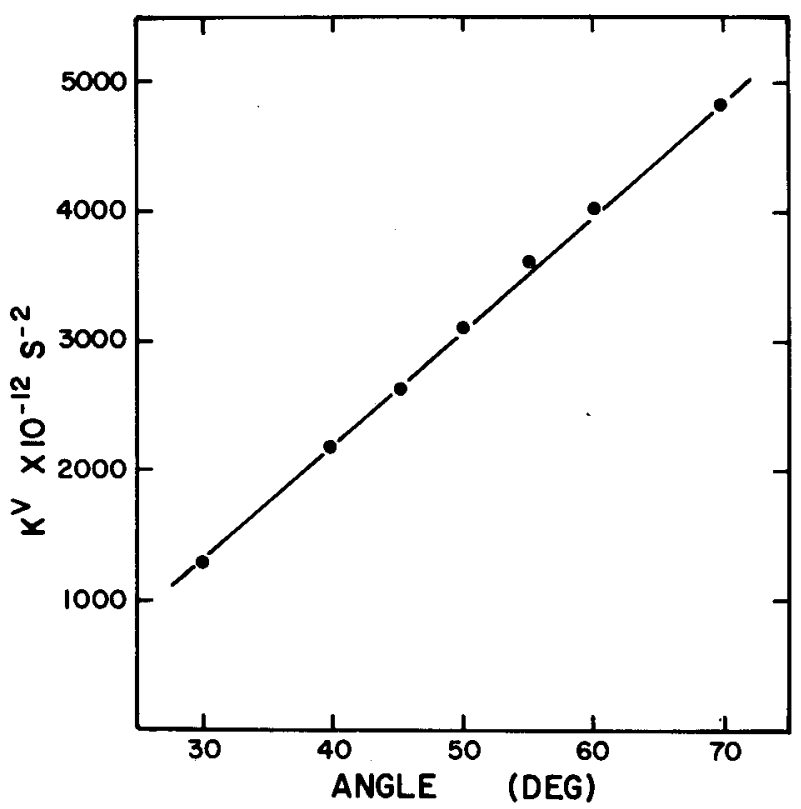

FIG. 4. The reliability factor variation with angle separation of intersecting beams for the ELDORA scanning procedure. The sample volume top was assumed to be $14 \mathrm{~km}$ and the aircraft flight altitude $5 \mathrm{~km}$. Thus the volume considered is $40 \times 40 \times 14 \mathrm{~km}$. For such an aircraft there is an identical pattern on the opposite side of the aircraft. Thus, in a single flight leg, the total $\kappa^{V}$ is twice that shown.

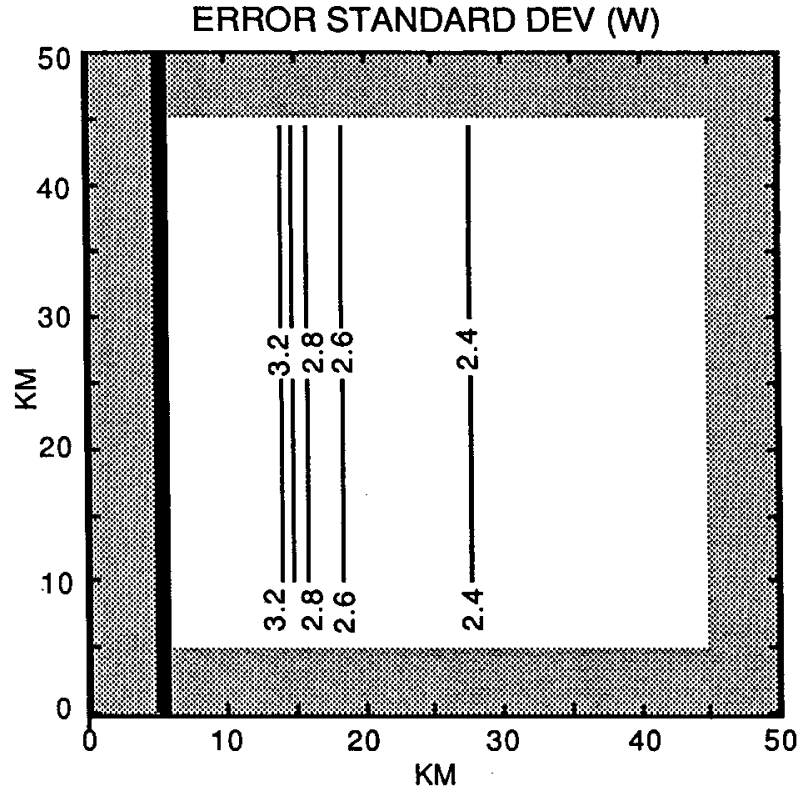

FIG. 5. Errors from ELDORA sampling procedure expressed as standard deviation with units of $\mathrm{m} \mathrm{s}^{-1}$. Aircraft flight altitude is 5 $\mathrm{km}$ and the storm is assumed to have a height of $16 \mathrm{~km}$. Aircraft track is heavy solid line. Mirror image field on the other side of the aircraft is omitted.

is less than $90^{\circ}$ for the cases evaluated here. If angles of intersection are greater than $70^{\circ}$, the time to acquire the data becomes longer than for the two-leg pattern. For an intersection angle of $90^{\circ}$, the flight time is $50 \%$ longer than the time for the two-leg mode. However, it must be kept in mind that this evaluation is restricted to only one side of the aircraft, and that the value of the quality index and the total volume sampled are doubled when data from both sides of the aircraft are considered.

\section{b. NOAA Airborne Doppler radar with one ground- based radar}

An important application for airborne radar is to collect data in conjunction with a ground-based radar. One advantage is that the data can be collected in about one-half the time. For certain flight patterns, one could collect data suitable for triple-Doppler analysis in the time required for a flight pattern suitable for an "aircraft-only" dual-Doppler analysis. For the most effective analysis, the data collection must be in regions where the ground-based radar and the airborne radar beams intersect as orthogonally as possible. For illustration we have presented the case where the aircraft flight pattern is displaced $20 \mathrm{~km}$ from the radar in Fig. 1e. Other distances from the radar are considered for comparison and are included in Table 1.

A typical flight pattern in association with a single ground-based radar interrogates an area over an order 


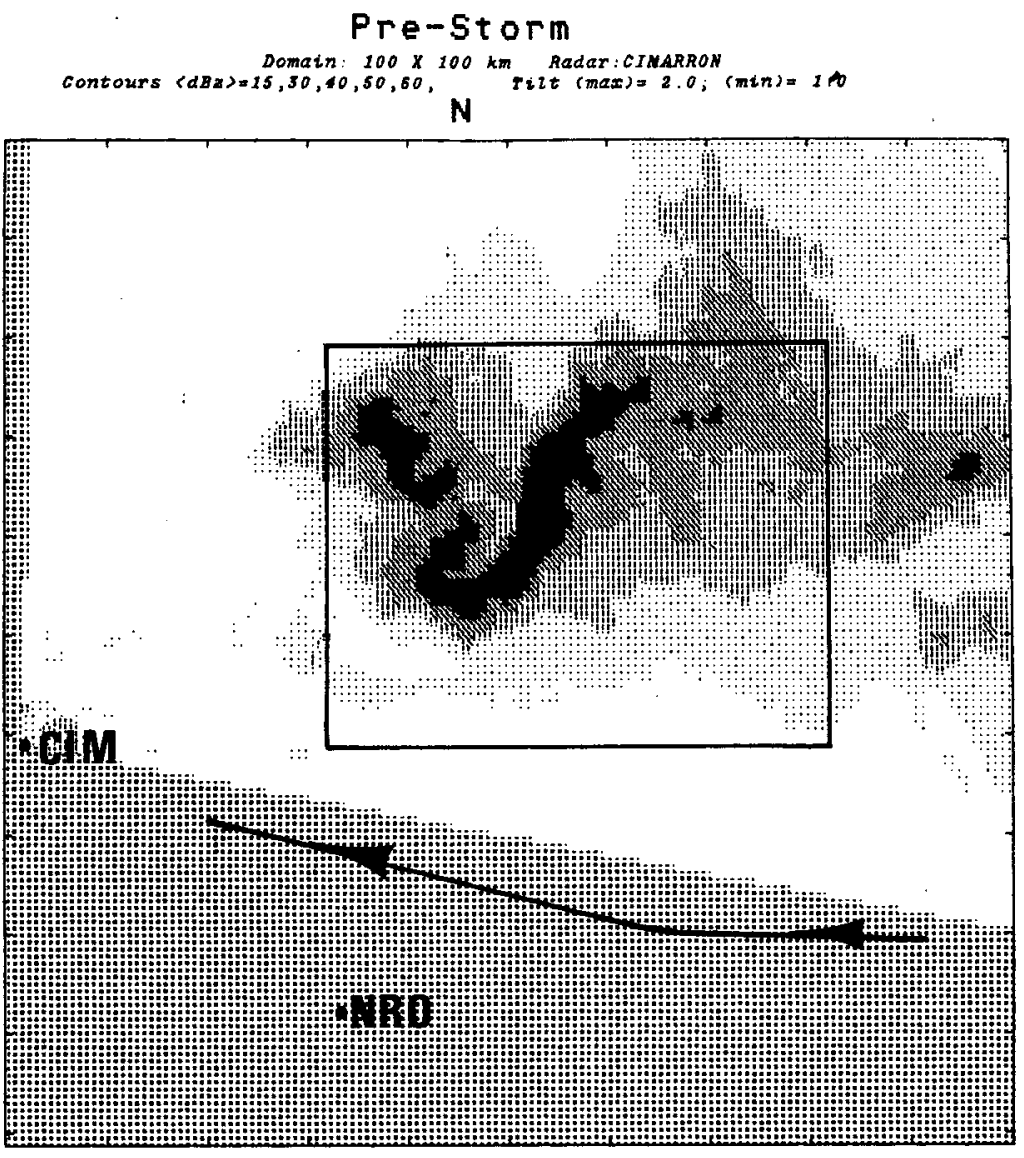

A cursor position (from radar): $-2.0 ;-40.0(\mathrm{~km})$

\section{$041319 Z \quad 5 / 26 / 85$}

FIG. 6. Low-level reflectivity pattern from the CIM radar at 0413:19 UTC on 27 May 1985. The box represents the Doppler analysis domain $(50 \mathrm{~km} \times 40 \mathrm{~km})$. The locations of the NSSL's Norman (NRO) and Cimarron (CIM) S-band Doppler radars are shown. The flight track of the P-3 aircraft during the data collection period is shown by the line with arrows. The shading represents contours of $15,30,40,50$, and 60 $\mathrm{dBZ}$, with the hatched region representing the azimuthal limits of the radar sector scan.

of magnitude larger than possible in the same time by a pattern using aircraft alone. This substantial increase in area (volume) leads to a corresponding increase in the $\kappa^{V}$ index value. When this is normalized by the interrogated volume, the mean value is comparable to those found for aircraft data alone. Large errors persist when the two radar beams are nearly colinear, with the smallest error located away from the plane (where maximum elevation angles will be a minimum) and where the beam intersection angles are greater than $60^{\circ}$ or so. The "best" field, from the maximum value of $\kappa_{V}{ }^{N}$ is when the aircraft passes directly over the radar. This is because it is this configuration which maximizes the average intersection angle between radar beams. But the optimum distance from the radar in which to fly will be determined by the location of the storm and the desire to obtain a good synthesis there. It should be kept in mind, however, that the orientation of the leg is arbitrary and that there are many geometries which will interrogate a given storm-scale area. Other considerations (e.g., air traffic control restrictions) can degrade the wind synthesis quality.

\section{c. NOAA Airborne Doppler radar with two ground- based radars}

It is heuristically obvious that a useful flight pattern for an aircraft with the NOAA scanning pattern in conjunction with ground-based radars would be to fly parallel to the radar baseline, displaced at least $20 \mathrm{~km}$, or toward and away from the radar, or in such a way as to utilize the quasi-vertical pointing information.

The value of airborne Doppler radar in this instance is to extend coverage, or to provide more accurate es- 
timates of the wind field. For example, a storm may be located between the radars or along the baseline direction. Airborne data also allows the use of tripleDoppler techniques when incorporating data from two ground-based radars, if the aircraft flies close enough such that the elevation angles are generally $>60^{\circ}$.

We have considered two obvious geometries, one in which the airplane flies perpendicular to the baseline and the other where the flight is parallel to the baseline. The principal advantage of flying parallel to the baseline is that this pattern enables use of the direct solution (triple-Doppler analysis), where only dual-Doppler analysis was possible, and to extend analysis to the baseline region. Sample flights are shown in Figs. If $-\mathrm{h}$.

The overall contribution of the aircraft data to the dual-Doppler analysis is seen in a two- to three-fold increase in the $\kappa^{V}$-index. Both the $\kappa^{V}, \kappa_{N}{ }^{V}$ and area covered are larger for flights parallel to the baseline in contrast to flights perpendicular to the baseline. This means that not only do flights parallel to the baseline increase the area interrogated, but they, on the average, decrease the error by a factor of 2 from that of ground-based radar alone.

\section{d. Advection and evolution effects}

Advection errors can, in principle, be corrected if the proper advection velocity is known. The usual assumption is that the storm is moving as a unit and that by correlating successive reflectivity or velocity fields the storm motion can be deduced. Then it is only a matter of advecting the data point while preserving the proper geometric relationship with the radar. If the chosen advection speed is incorrect or if different parts of the storm are moving at different speeds, then the synthesized fields will be degraded. The problems are identical to those for ground-based radars, but exaggerated because of the longer collection times for aircraft " $L$ " patterns.

In addition to translating, the storm also may be evolving. The effects of incorrect advection and storm evolution are similar, and there is no known correction for problems caused by evolution. The remedy is to make collection times as short as possible, particularly if it is suspected that the storm may be rapidly evolving. The further the points that are being combined are displaced in time, the greater the error. This means that the extreme ends of an " $L$ " pattern, while best from a geometric perspective, are also where storm evolution will have its greatest degrading effect.

\section{Example}

To illustrate the feasibility of combining airborne and ground-based Doppler radar data to yield a meaningful wind synthesis, we present an example of an Oklahoma supercell thunderstorm from data collected almost simultaneously by the NOAA P-3 (aircraft N43) and the two S-band ground-based Doppler radars op- erated by NOAA's National Severe Storms Laboratory (NSSL), Norman (NRO) and Cimmaron (CIM). The aircraft and ground-based radars were operated as part of the Oklahoma-Kansas Preliminary Regional Experiment for STORM-Central (PRE-STORM). For a complete description of O. K. PRE-STORM see Cun-
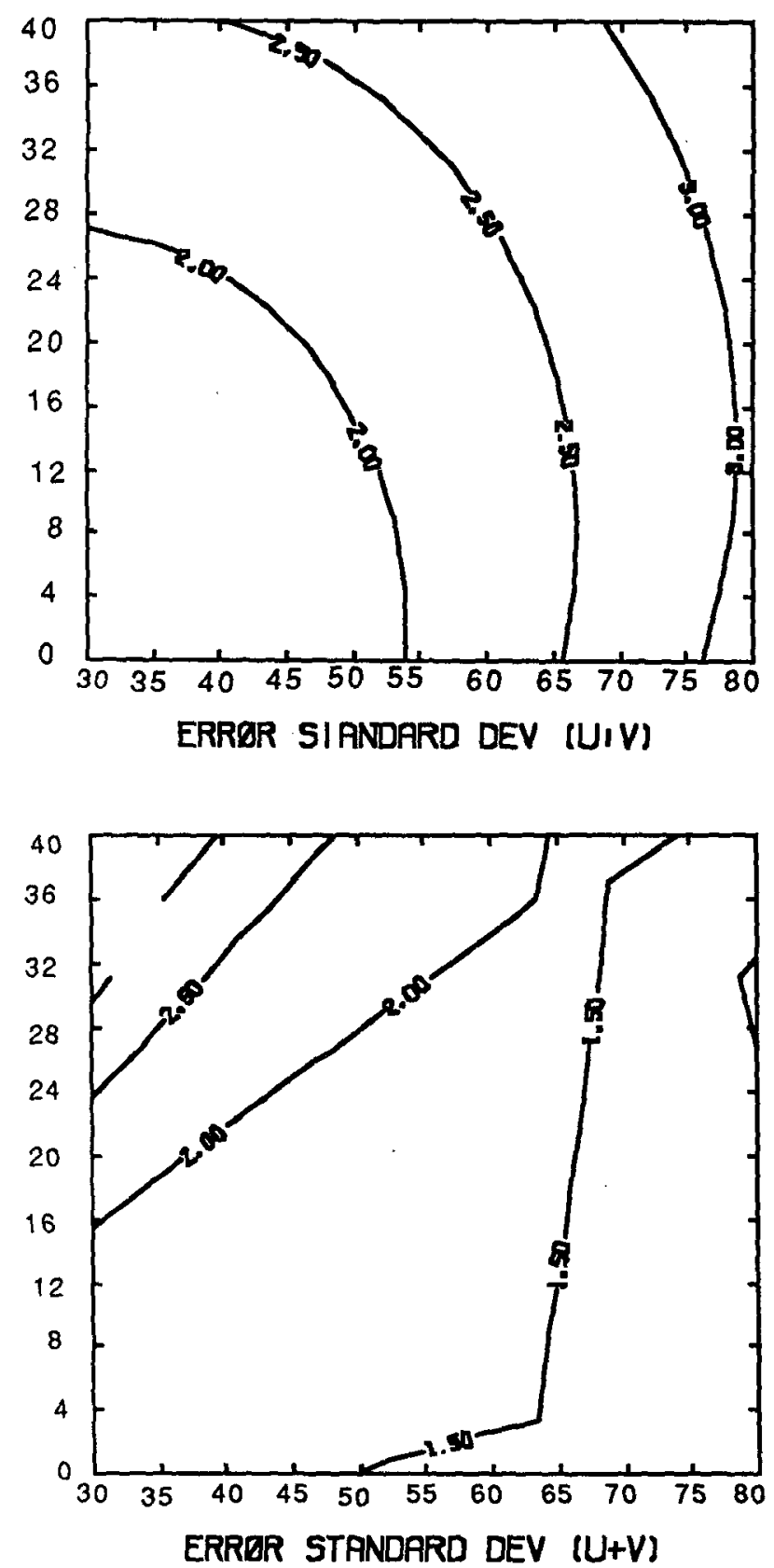

Fig. 7. Error variance distributions of the uncertainty of the divergence field at $4 \mathrm{~km}$ height for the 27 May example. Flight level is $2.8 \mathrm{~km}$ and uncertainty fields are given for the combination of (a) Norman and Cimarron ground-based radars and (b) the Cimarron ground-based and the P-3 airborne radar. The geometry is shown in Fig. 6. 


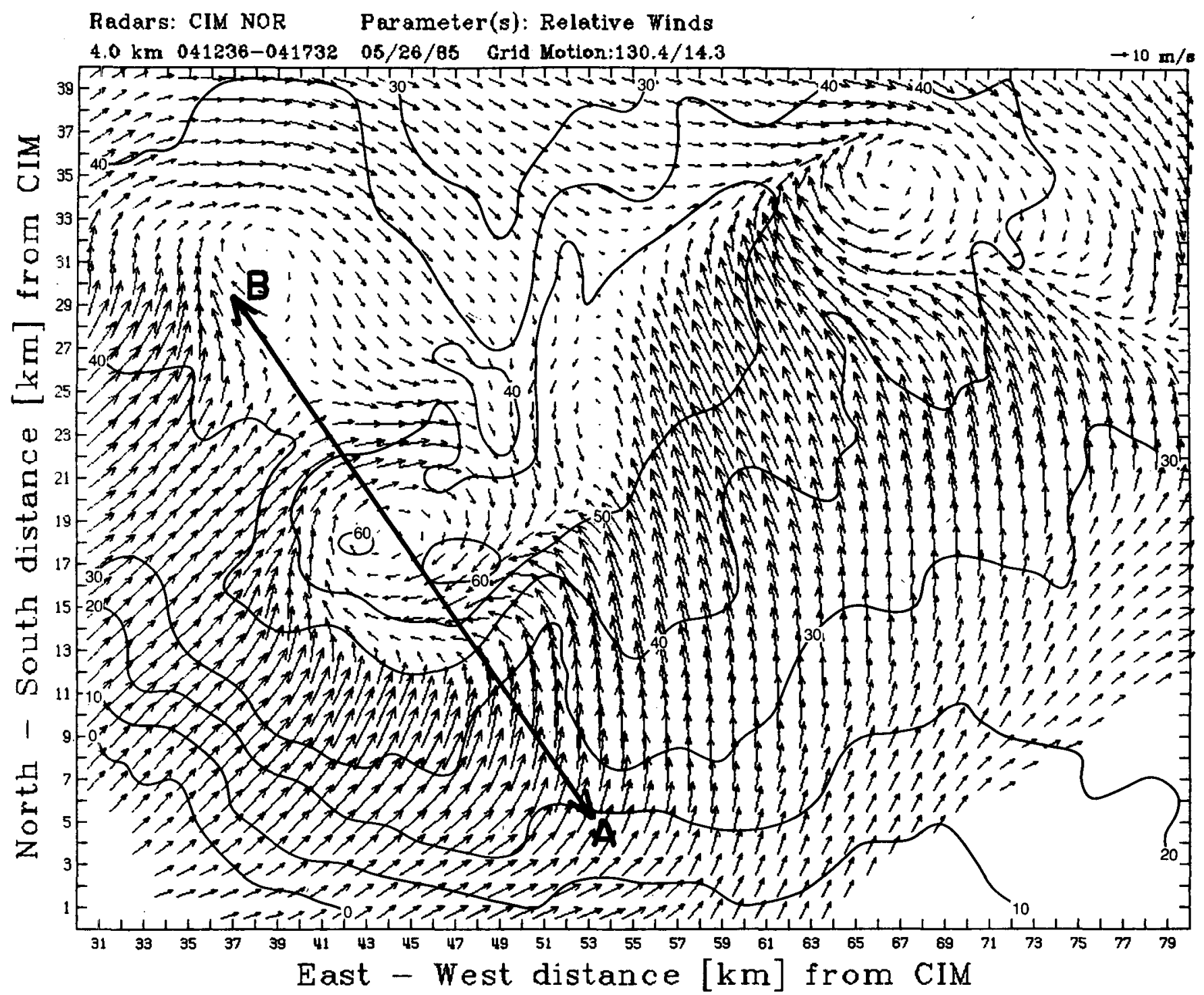

FIG. 8. Storm-relative horizontal winds and reflectivity fields at $4 \mathrm{~km}$ synthesized from (a) N43-CIM radars, and (b) NRO-CIM radars. Line segment A-B indicates the location of the vertical cross section shown in Fig. 10. Solid contours are reflectivity every $10 \mathrm{dBZ}$.

ning (1987). During the early evening of 27 May 1985 , a convective storm developed north of the Cimarron radar and reached maturity as it propagated through the northeast lobe of the NRO-CIM dual-Doppler network. The airborne data presented here is from the part of the N43 flight form 0407:00 to 0417:20 UTC as the aircraft headed westnorthwest toward CIM. This data are merged with a CIM volume scan from 0412: 40 to 0416:41 UTC. The N43-CIM synthesized wind field is compared to a conventional NRO-CIM dualDoppler analysis for the time period 0412:40-0417: 32 UTC.

The N43 flight track is shown relative to the storm, NRO, and CIM in Fig. 6. The echo pattern resembles an anticyclonic hook echo pattern indicative of strong anticyclonic flow. Supporting the supercell hypothesis, the echo pattern maintained itself for over $20 \mathrm{~min}$ after 0413 UTC as the storm propagated to the southeast at about $15 \mathrm{~m} \mathrm{~s}^{-1}$. During the data-gathering period, the storm dropped softball-sized hailstones on an NSSL chase team near the town of Edmond, Oklahoma. Maximum reflectivity was in the southeast flank (front) of the storm. Lighter, more stratiform, precipitation fell ahead and to the left of the storm track from the extensive anvil that extended $>50 \mathrm{~km}$ to the northeast. The analysis domain $(40 \times 50 \mathrm{~km})$ is indicated by the box. Grid points in the analysis domain were spaced $1 \mathrm{~km}$ apart in the horizontal, and $0.5 \mathrm{~km}$ in the vertical. During data collection the aircraft was flying at a constant altitude of $2.8 \mathrm{~km}$ above the ground. 


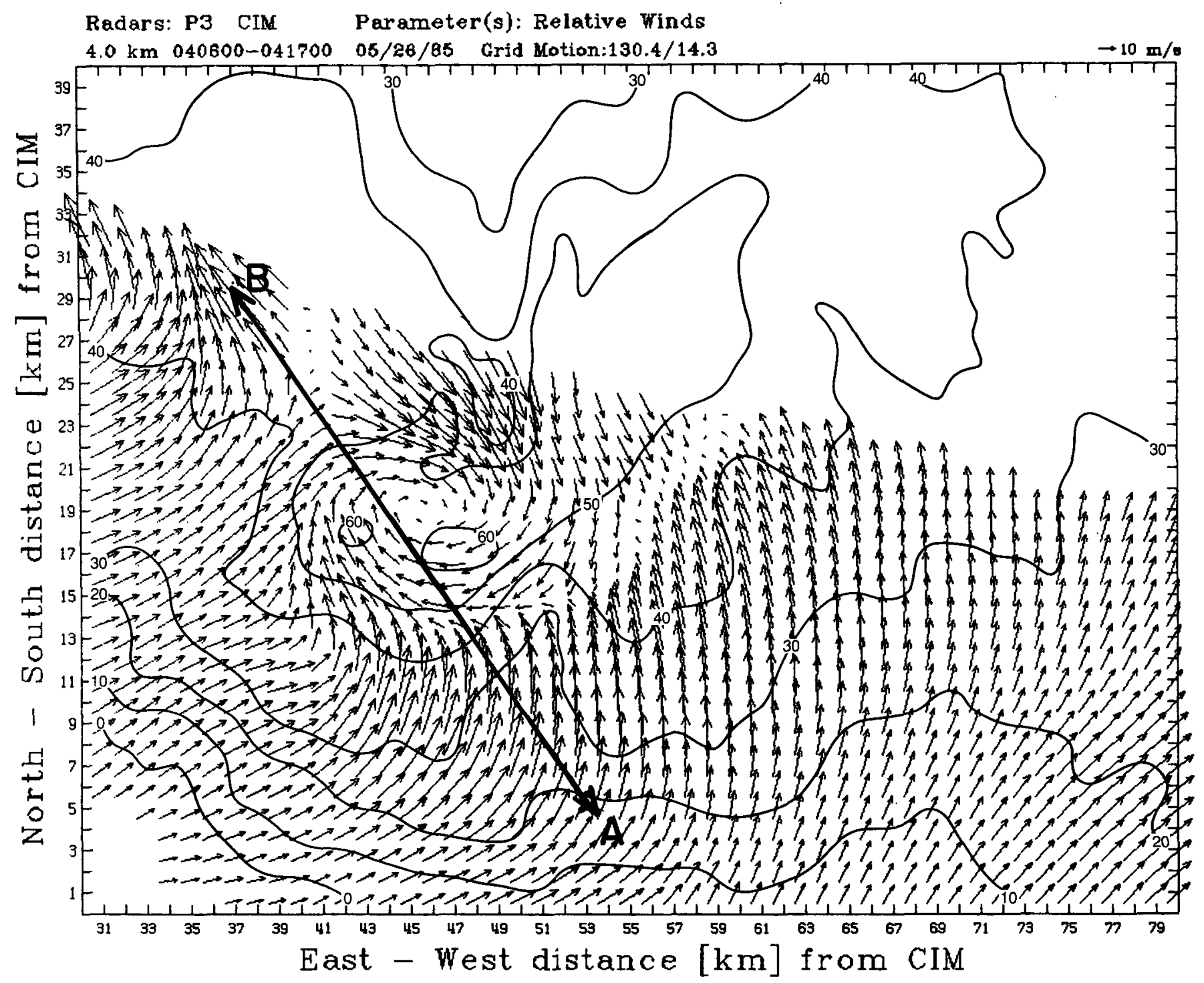

FIG. 8. (Continued)

Assuming interpolated uncertainty in the radial velocity estimates of $1 \mathrm{~m} \mathrm{~s}^{-1}$, the expected uncertainty, expressed as the square root of the variance of the uncertainty in the sum of the $u$ and $v$ wind components, is shown in Fig. 7. Figure 7a shows the distribution of that uncertainty at $4 \mathrm{~km}$ height for the $50 \times 40 \mathrm{~km}$ analysis domain outlined in Fig. 6 . The uncertainty slowly increases from the SW to the NE part of the analysis domain. The uncertainty due to geometry is small due to the favorable location of the analysis domain relative to the radar location. In Fig. $7 \mathrm{~b}$, data from the P-3 flight legs (shown in Fig. 6) and the Cimarron radar are considered. In this case the minimum uncertainty is in the SE with uncertainty increasing toward the NW. The uncertainty is of comparable magnitude. Examining Figs. 8a, b, the P-3/Cimarron analysis (Fig. 8b) is more limited in coverage than that from the two ground-based radars, due to the $40-\mathrm{km}$ range of Doppler radar data from the aircraft. It is also seen that the discrepancy between the two fields is greatest toward the NW corner. This difference is larger than predicted by the error model, but is qualitatively in agreement.

The radial velocity data were converted to Cartesian wind components using the overdetermined dualDoppler analysis technique (see Appendix for details) using the equation of continuity to close the equation set (Eq. A4). The data were first interpolated to Cartesian $(x, y, z)$ coordinates using a Cressman analysis with a horizontal and vertical influence radius that varied with range according to

$$
\begin{aligned}
& R_{v}=r \tan (\phi) \\
& R_{h}=r \tan (\Theta)
\end{aligned}
$$




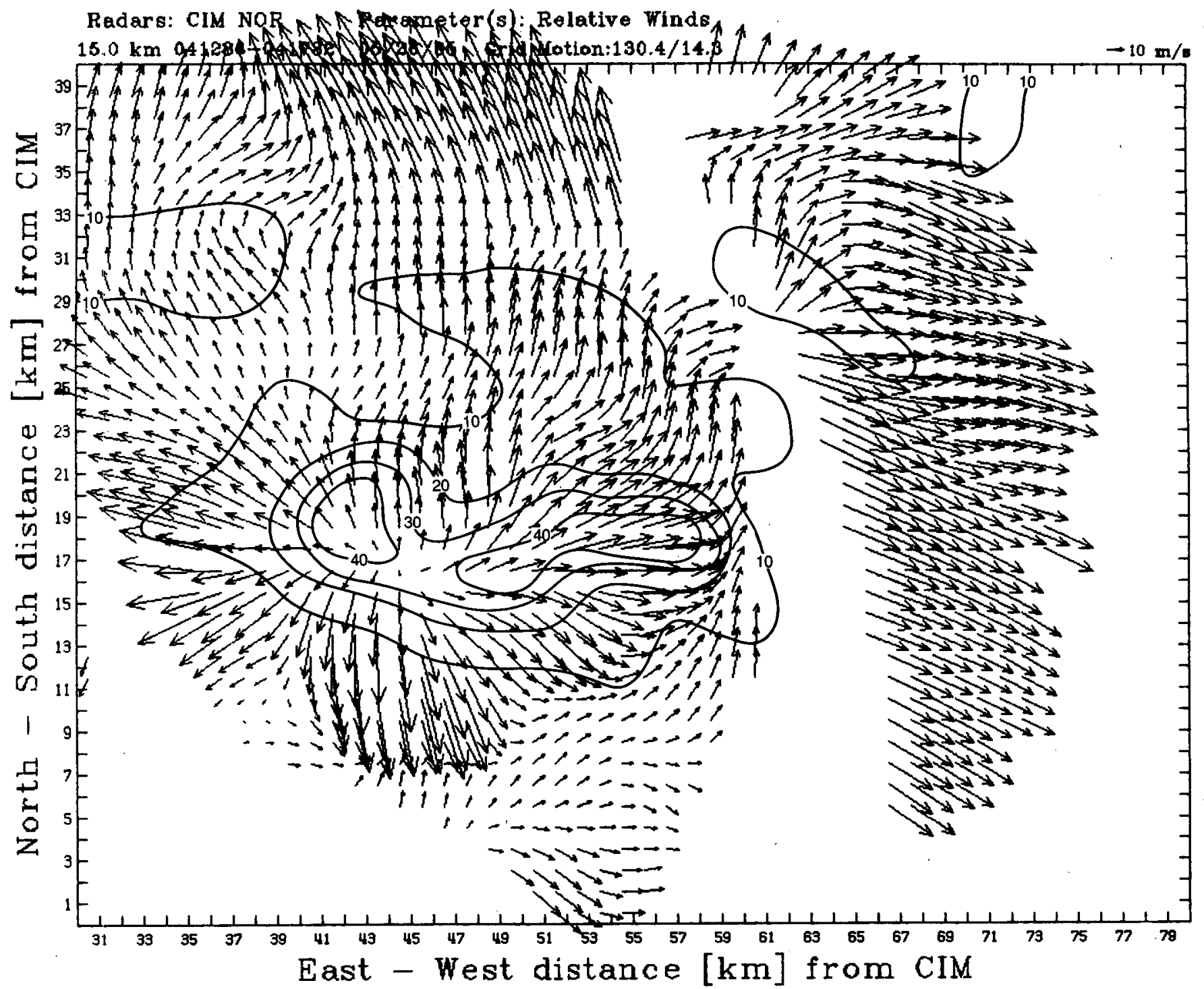

FIG. 9. As in Fig. 8, except for a height of $15 \mathrm{~km}$.

where $R_{h}$ is the horizontal influence radius [km], $R_{v}$ the vertical influence radius, $r$ the range $[\mathrm{km}]$ to the Cartesian point $[\mathrm{km}], \phi$ the vertical beam width [deg], and $\Theta$ the horizontal beam width [deg]. The aircraft's flight track was deemed too far away from the storm's main updraft to use the direct (triple Doppler) method of solution. The horizontal flow field at $4 \mathrm{~km}$ within the analysis domain is shown for both the N43-CIM and NRO-CIM synthesis in Fig. 8. The winds are storm relative. The radar locations and data were advected to their probable positions at 0413:19 UTC in an attempt to account for storm advection during the datagathering period. Only about one-half of the synthesized winds are available from the domain (Fig. 8a) in the N43-CIM analysis due to the relatively short range $(\sim 40 \mathrm{~km})$ of the airborne Doppler processor. In a qualitative sense, the basic circulation features associated with the main reflectivity maxima and the hooklike appendage near coordinate $(47,17)$ are reproduced in both analyses. An anticyclonic mesovortex centered just to the north of the highest reflectivity is the dominant circulation feature near the hook-like appendage. A convergence line can be seen along the southern flank of the reflectivity maxima extending to the western side of the storm. The reflectivity maxima is displaced to the north of the maximum convergence suggesting that the updraft may tilt with height toward the north (downshear).

Although the two horizontal wind fields are qualitatively very similar, subtle differences exist which may be explained by inherent differences in the radar systems, rather than deficiencies of the analysis techniques. 


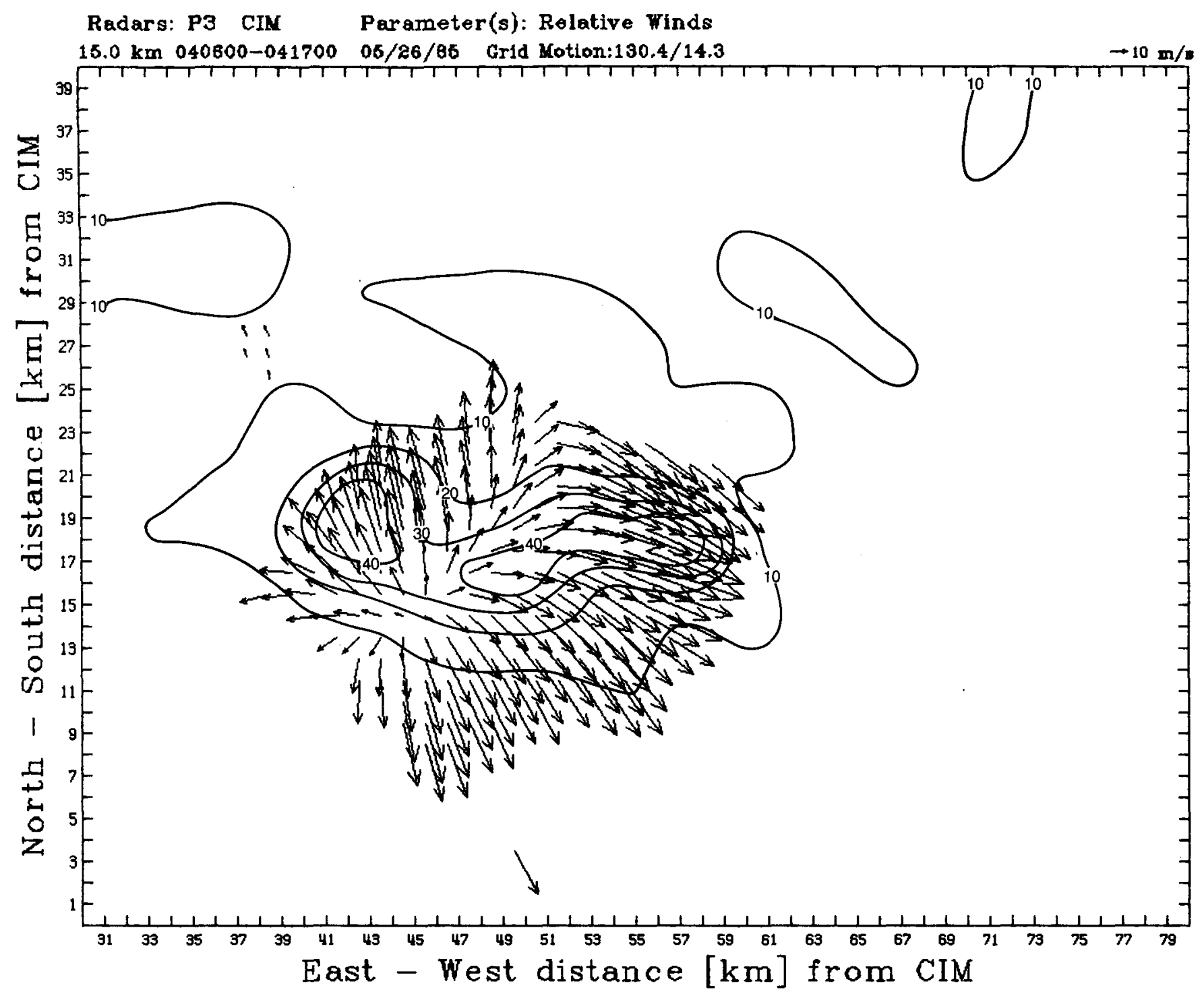

FIG. 9. (Continued)

For example, stronger northwest flow is evident to the north of the reflectivity maxima (located at approximate coordinates $x=50, y=24$ ) in the N43-CIM analysis than the NRO-CIM analysis. This difference may be explained by the broader vertical beam width of the airborne radar $\left(2^{\circ}\right.$ vs $\left.1^{\circ}\right)$ and the range from the $\operatorname{radar}(\sim 40 \mathrm{~km})$. Much stronger northwest flow in that region was evident in the NRO-CIM analysis at levels above $4 \mathrm{~km}$, so it is possible that the larger vertical beam volume of the airborne radar at that range (compared to the NRO radar) caused the winds to be biased due to the larger vertical integration in the high shear region.

The divergent wind field at $15 \mathrm{~km}$ height, for both analysis, is shown in Fig. 9. The divergence maximum is associated with the reflectivity maxima at this height.
More wind vectors are evident in the NRO-CIM analysis due to the better sensitivity of the ground-based radars compared to the airborne radar.

A vertical cross section along the line segment A-B of Fig. 8 ( $324.7^{\circ}$ azimuth) is shown in Fig. 10 and Fig. 11. This cross section is representative of the flow through the main updraft and mesocyclone. Both analyses are qualitatively similar. An elevated convergence zone is evident $5-7 \mathrm{~km}$ in front of the region of maximum reflectivity with substantial echo overhang ahead of the storm track (Figs. 10a and 11a). The main updraft slopes to the northwest over the high-reflectivity core with surprisingly little downdraft evident in the high-reflectivity zone. A comparison of the vertical velocities (Fig. 11 a and Fig. 11b) reveals good agreement in the pattern and magnitudes. The maximum updraft 


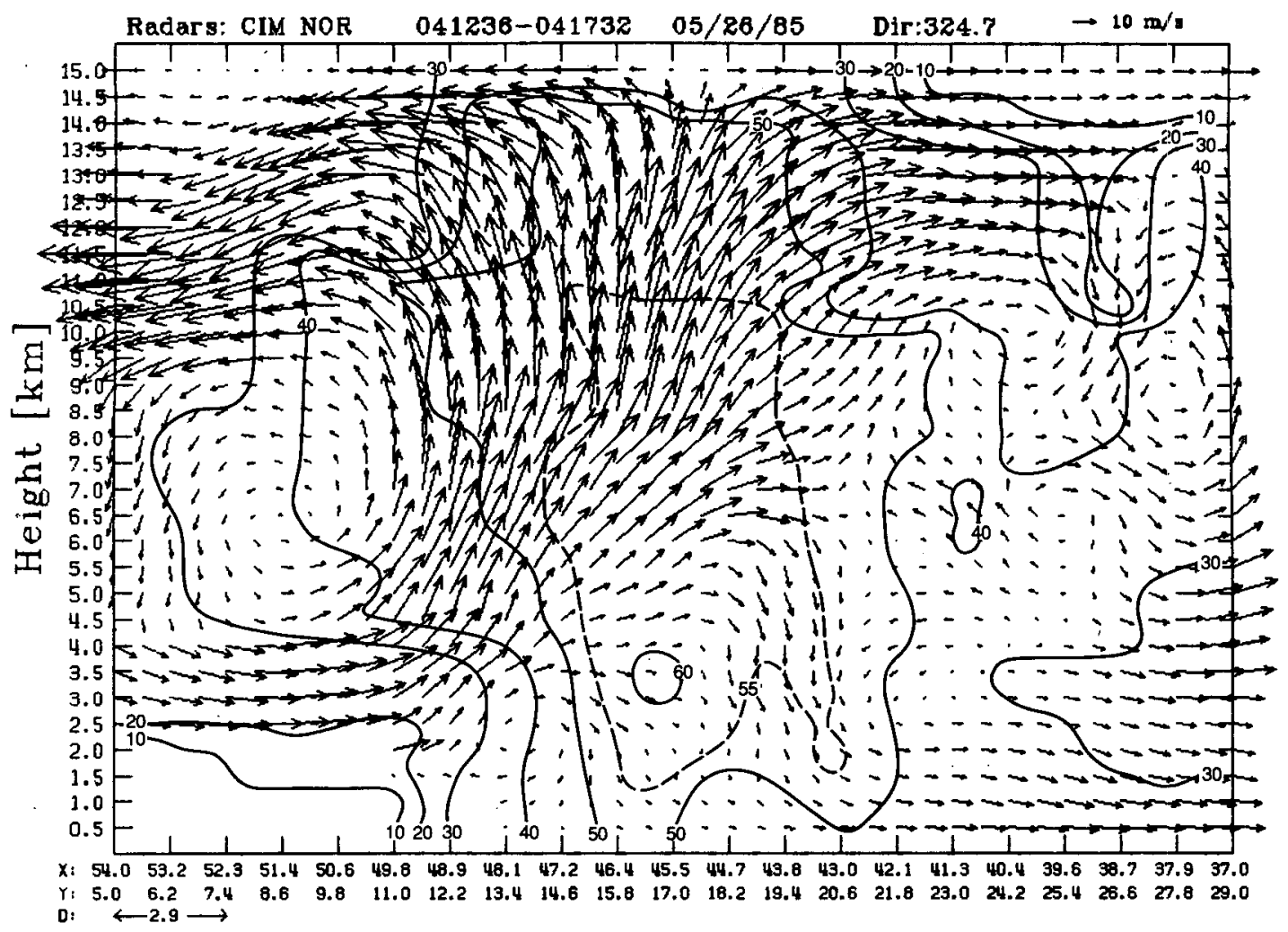

Distance $[\mathrm{km}]$ from CIM

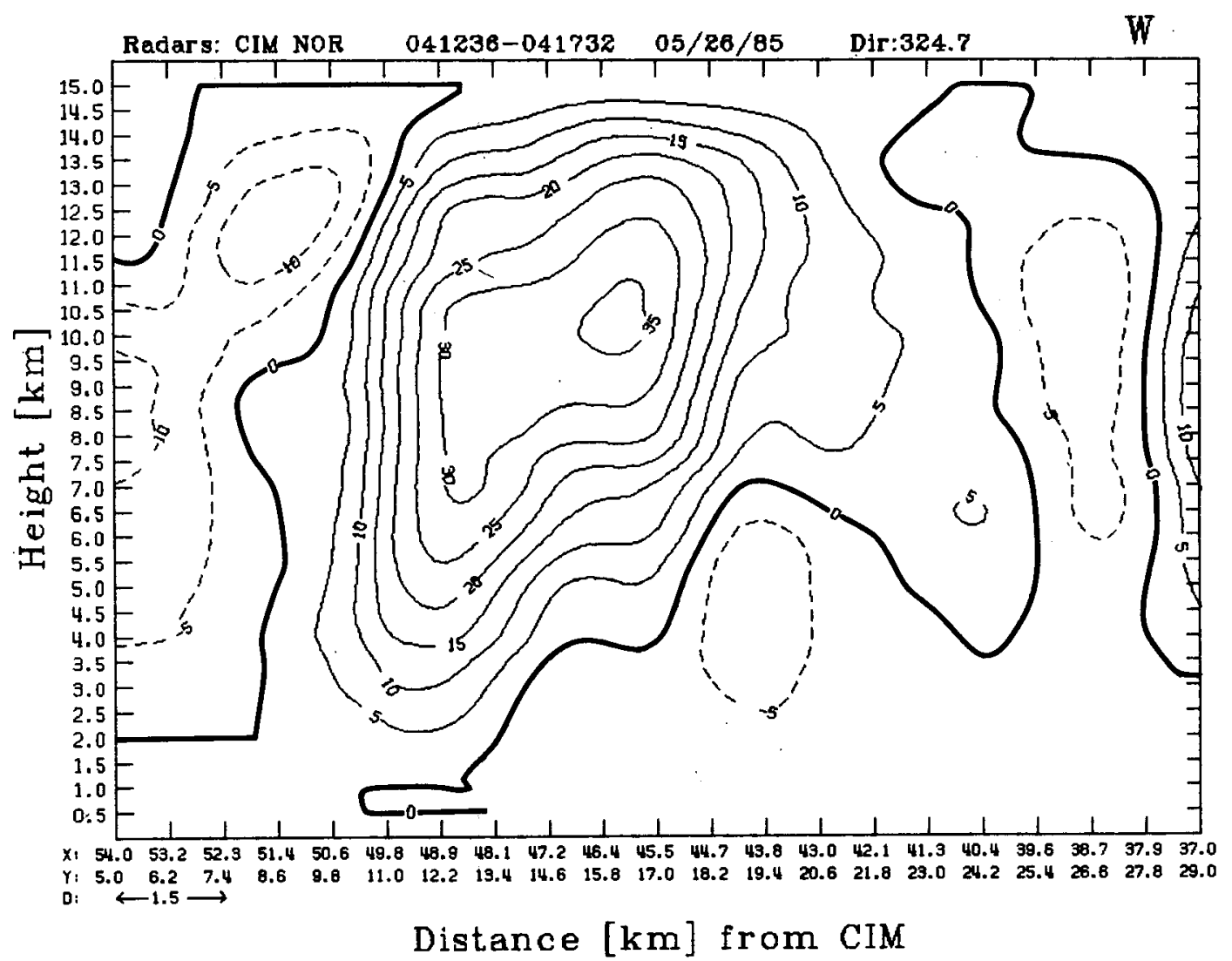

FIG. 10. Vertical cross section along the line segment A-B shown in Fig. 8 from the N43-CIM synthesis of (a) storm-relative winds and radar reflectivity $[\mathrm{dBZ}]$, (b) vertical velocity $\left[\mathrm{m} \mathrm{s}^{-1}\right]$ and (c) horizontal wind component in the plane [m $\left.\mathrm{s}^{-1}\right]$. In (b) and (c) the dashed contours represent negative velocities. Horizontal length of the cross section is about $30 \mathrm{~km}$. 


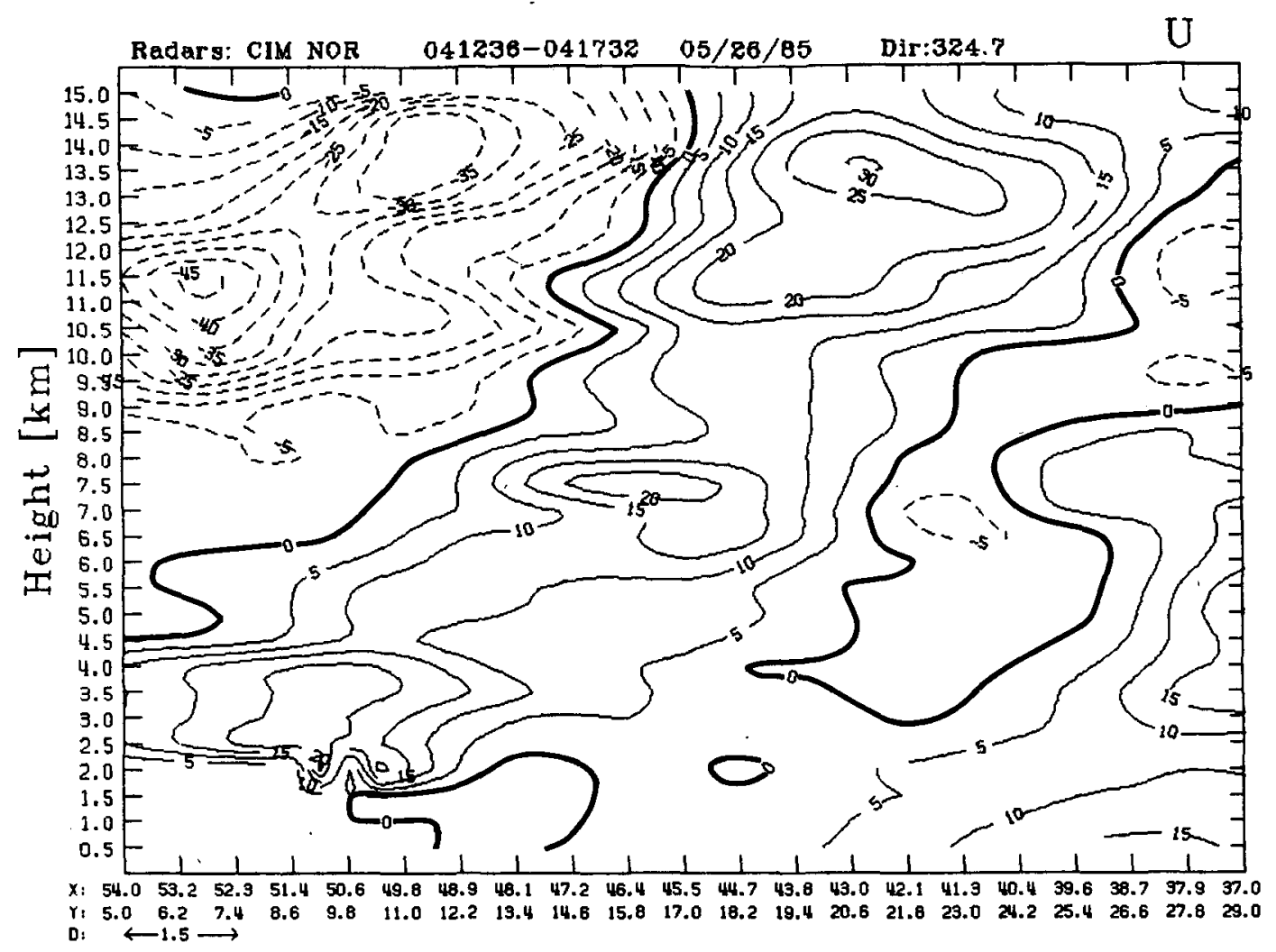

Distance $[\mathrm{km}]$ from CIM

FIG. 10. (Continued)

was about $5 \mathrm{~m} \mathrm{~s}^{-1}$ higher in the N43-CIM analysis in the N43-CIM analysis than the NRO-CIM analysis. The downdraft magnitude was also slightly greater. The explanation for this discrepancy may be the differences seen in near-cloud top divergence of Fig. 10c and Fig. $11 \mathrm{c}$. Although divergence is three-dimensional in nature, the consistently lower values of $u$ seen at the top of the cross section $\left( \pm 35 \mathrm{~m} \mathrm{~s}^{-1}\right.$ vs $\left.\pm 20 \mathrm{~m} \mathrm{~s}^{-1}\right)$ suggest that the differences in vertical velocity magnitude might be caused by differences in observed cloud top divergence. Other cross sections that were constructed orthogonal to the one presented reveal similar patterns. The stronger near-top divergence in the N43-CIM analysis is probably due to better sampling of the winds at cloud top by the airborne radar compared to NRO since the elevation steps in the ground-based radar were $>3^{\circ}$ near the end of the volume scan. It is also possible that a better estimate of near surface divergence was made by the airborne radar because of its viewing position that resulted in a stronger downdraft in the highreflectivity zone.

\section{Summary}

The following list of generalizations is meant to serve as a guide on the use of airborne Doppler radar. It would not be difficult to design a situation that would represent an exception to one or more of these gener- alizations. However, this list is a useful guide for using airborne Doppler radar to study convection:

- Close to the flight path, the errors are large except when the flight path is through a ground-based dualDoppler lobe, and triple-Doppler analysis techniques can be used.

- Storm top height affects analysis accuracy. The value of $\kappa_{N}{ }^{V}$ was about $40 \%$ larger at $10 \mathrm{~km}$ than at 14 $\mathrm{km}$ for the same flight level.

- For pseudo dual-Doppler synthesis, the analysis over the entire volume is improved when the flight level is near the storm's middle level. The increase in $\kappa_{N}{ }^{V}$ for storms 10 and $14 \mathrm{~km}$ high was about $33 \%$ when going from a flight level of $1 \mathrm{~km}$ to $5 \mathrm{~km}$.

- If two legs are used, P-3 legs should be as close to right angles as is possible to maximize area and minimize errors over the synthesized area.

- The contribution of more than one leg near a ground-based radar is limited, especially if flight time (evolution effects) are considered to be important.

- To cover a large area, either long flights using short-leg segments must be used (in which evolution may degrade the meaning of one part of the synthesis to another), or a flight pattern is required which is characterized by a larger beam sampling volume and a longer time interval in which data are combined from different legs. 


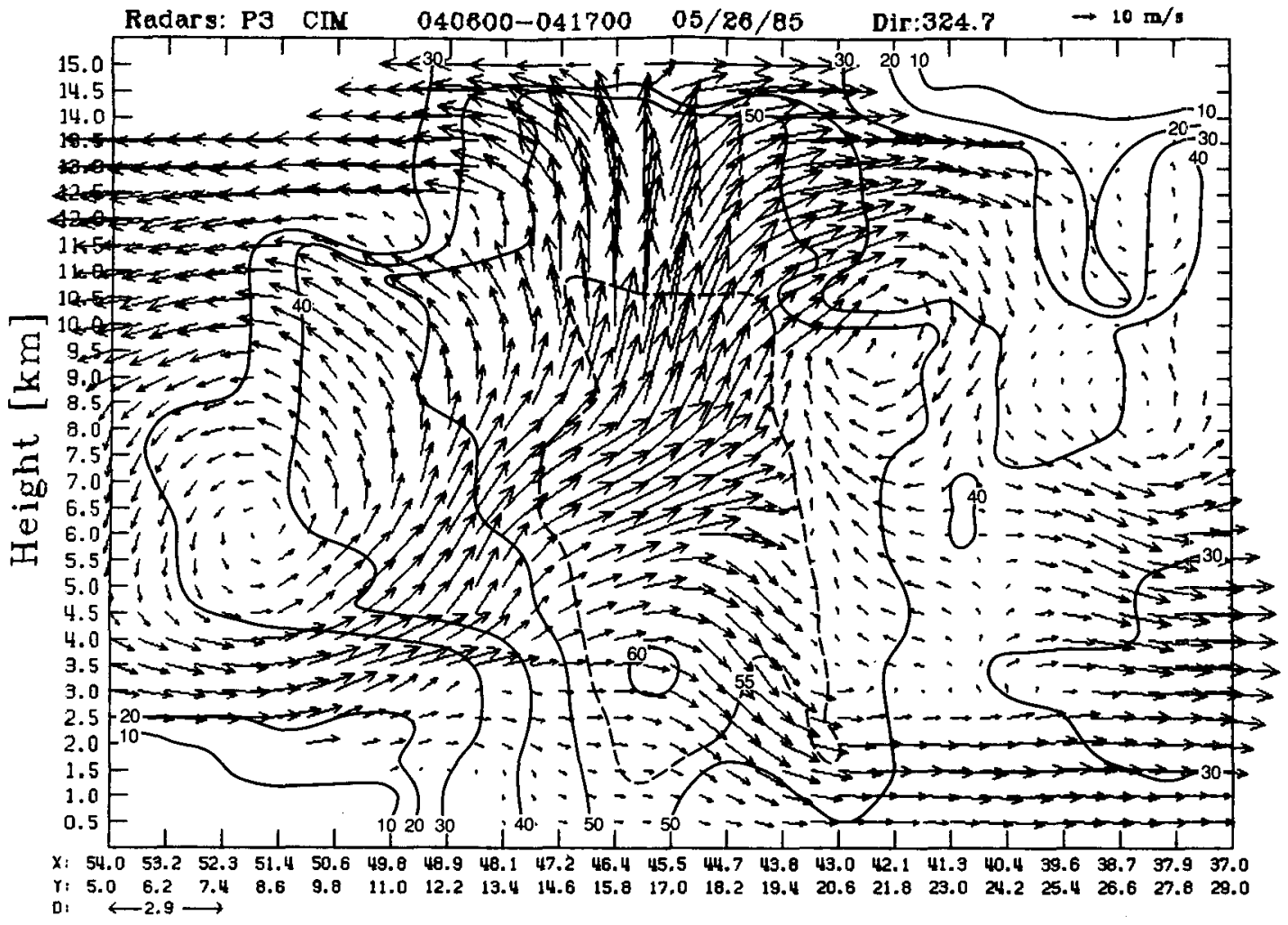

\section{Distance $[\mathrm{km}]$ from CIM}

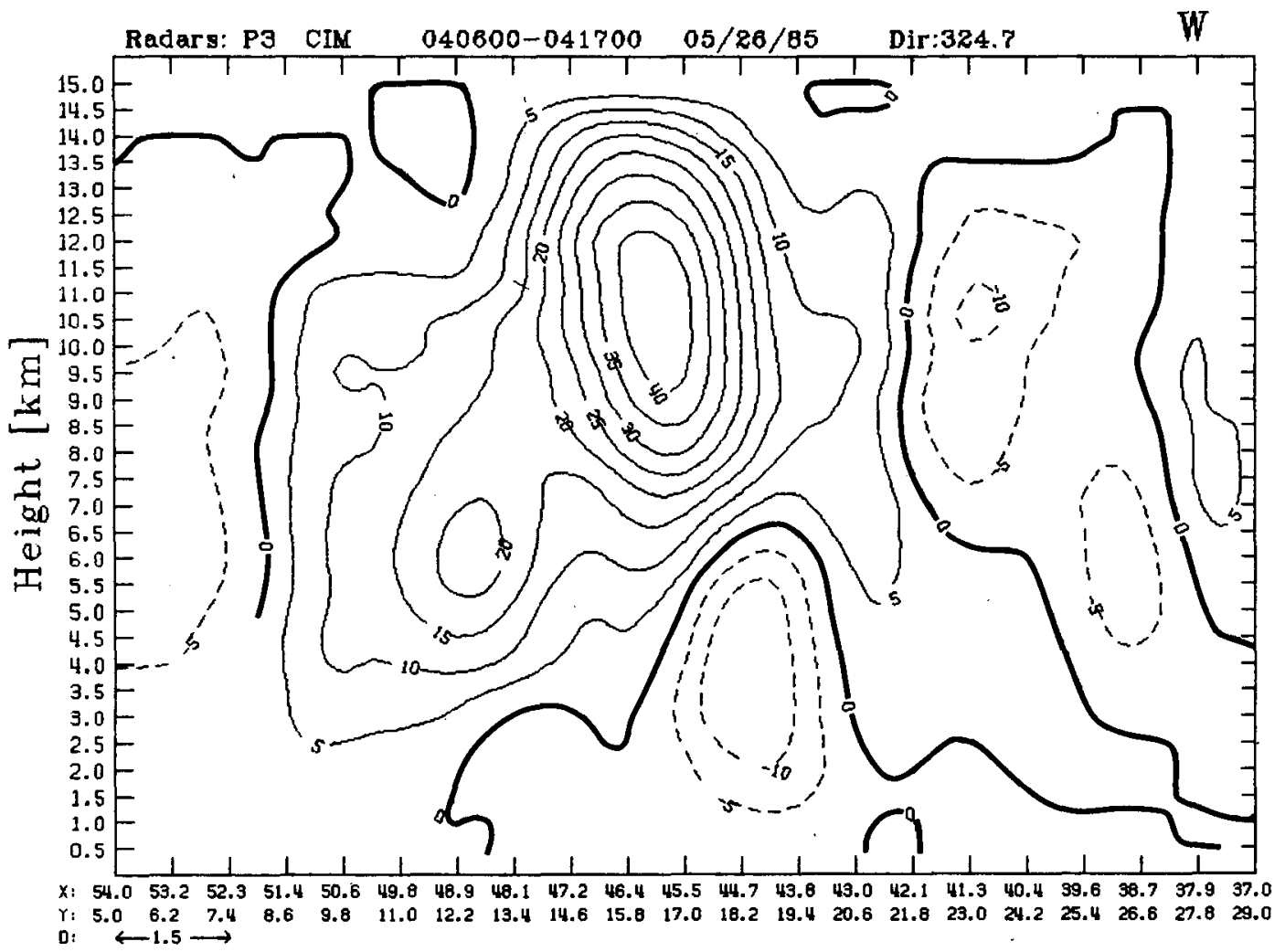

\section{Distance [km] from CIM}

FIG. 11. As in Fig. 10, except for the NRO-CIM synthesis. 


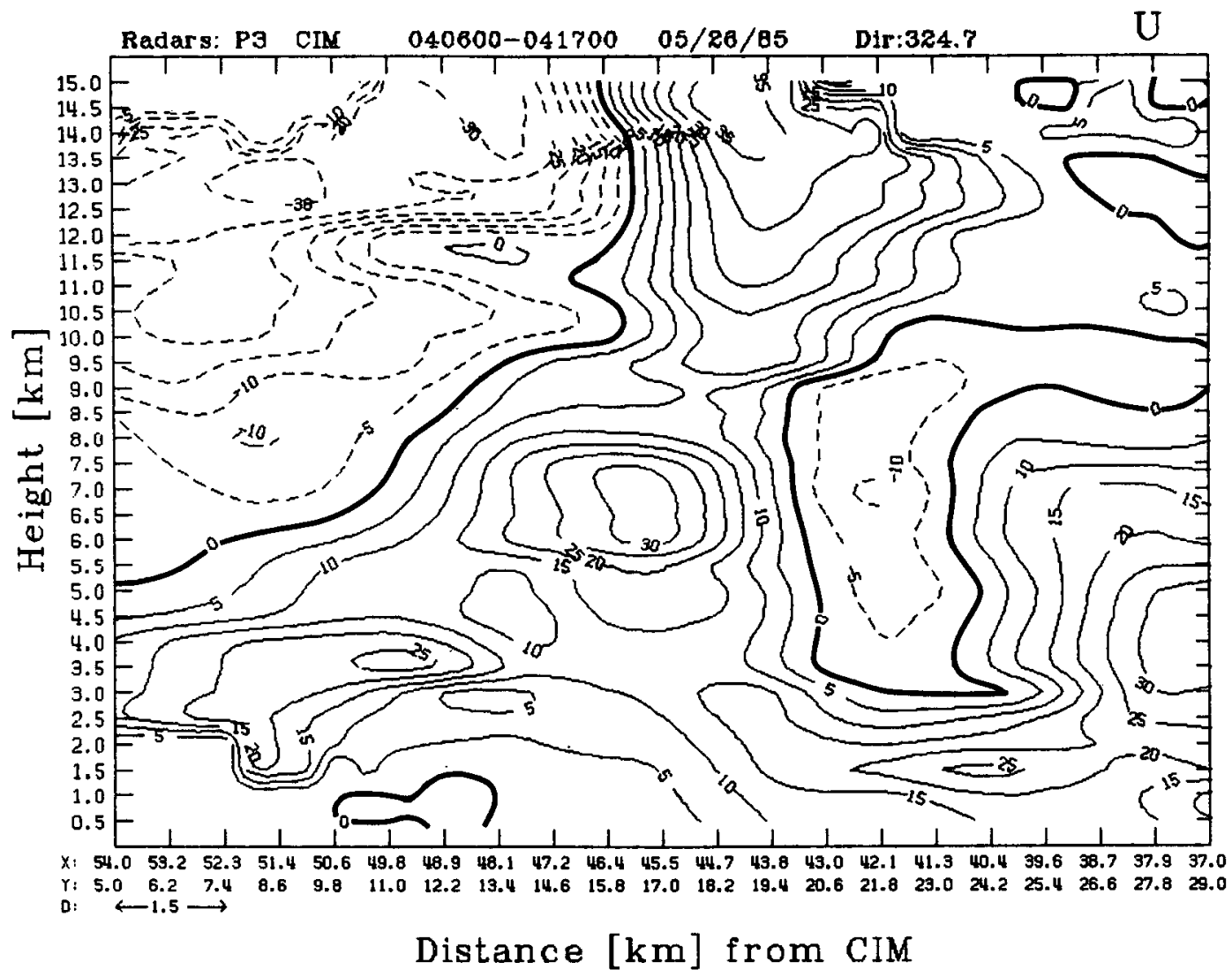

FIG. 11. (Continued)

- When combining data with a ground-based dualDoppler network, flights parallel to the baseline are generally better than those perpendicular to the baseline.

- A fundamental restriction of the NOAA P-3 system is the limiting range of $40 \mathrm{~km}$. Additional radar range gates, or a different gate spacing, could extend the distance, but the limitations of the radar beam width remain restrictive on the NOAA aircraft. With a narrower beamwidth, the range could be extended, allowing interrogation schemes at smaller elevation angles, reducing uncertainty.

- Neglecting other sampling restrictions, a single aircraft with a ground-based Doppler radar can retrieve data suitable for synthesis as well as a conventional ground-based dual-Doppler network. This is because of the aircraft's ability to maintain intersecting beam angles close to $90^{\circ}$ over a large portion of the groundbased radar's viewing area.

To synthesize the multiplicity of geometries possible, the pattern quality is computed for some of the cases considered here. One important point is that these values consider the "good" area of collection. If a storm is not located in a "good" area, it may not be possible to adjust the flight path to optimize a particular flight pattern, just as it is not possible to easily relocate ground-based radars.
Acknowledgments. Marianne Becker, Bill Bumgarner, Karen Johnson, Kenneth Johnson, Mary Alice Rose, Mary Stephenson and Sue-Lee Wang all assisted in performing the computations. This work was partially supported by NOAA Grant 40RANR608326 and NSF Grant ATM-8403452 to the University of Oklahoma and by NSF Grant ATM-8604143 and ATM8619957 to the Florida State University. Partial support was also provided by Department of Energy Contract DE-FC05-85ER250000 to the Florida State University Supercomputer Computations Research Institute.

\section{APPENDIX}

\section{Computation of Uncertainties}

If the aircraft, whose position is denoted by $\left(x_{i}, y_{i}\right.$, $z_{i}$ ) observes a point at $(x, y, z)$ then the radar will observe a radial velocity $V_{i}$ given by where

$$
u\left(x-x_{i}\right)+v\left(y-y_{i}\right)+W\left(z-z_{i}\right)=V_{i} R_{i}
$$

$$
\begin{gathered}
R_{i}=\left[\left(x-x_{i}\right)^{2}+\left(y-y_{i}\right)^{2}+\left(z-z_{i}\right)^{2}\right]^{1 / 2} \\
w=W-V_{t}
\end{gathered}
$$

\section{Overdetermined dual-Doppler method}

Following Ray et al. (1980), and using the approach described by Ray and Sangren (1983), the uncertainty in the vertical air motion, 


$$
\begin{gathered}
\sigma_{w k}^{2}=\frac{1}{4}\left\{1+\left[\frac{(1 / \Delta z)-(\kappa / 2)}{(1 / \Delta z)+(\kappa / 2)}\right]\right\}^{2} \sigma_{w(k+1 / 2)}{ }^{2} \\
+\frac{\sigma_{u}{ }^{2}}{2[2 \Delta x(1 / \Delta z+\kappa / 2)]^{2}}+\frac{\sigma_{v}{ }^{2}}{2[2 \Delta y(1 / \Delta z+\kappa / 2)]^{2}}
\end{gathered}
$$

is obtained from the equation of continuity,

$$
\frac{\partial u}{\partial x}+\frac{\partial v}{\partial y}+\frac{\partial w}{\partial z}-\kappa w=0
$$

where $\kappa$ is the logarithmic rate of change of density with height and the uncertainty of the horizontal wind components is

$$
\begin{aligned}
\sigma_{u}{ }^{2} & =\left\langle\sum _ { i } \sigma _ { v i } { } ^ { 2 } \left\{ R_{i}\left(x-x_{i}\right)\left[\sum\left(y-y_{i}\right)^{2}\right]-R_{i}\left(y-y_{i}\right)\right.\right. \\
\times & {\left.\left[\sum\left(x-x_{i}\right)\left(y-y_{i}\right)\right]\right\}^{2}+\sigma_{w}{ }^{2}\left[\sum\left(y-y_{i}\right)^{2}\right.} \\
\times & \sum\left(x-x_{i}\right)\left(z-z_{i}\right)-\sum\left(x-x_{i}\right)\left(y-y_{i}\right) \\
\times & \left.\left.\sum\left(y-y_{i}\right)\left(z-z_{i}\right)\right]^{2}\right\rangle \\
\times & \quad \sum\left(x-x_{i}\right)^{2} \sum\left(y-y_{i}\right)^{2} \\
& \left.-\left[\sum\left(x-x_{i}\right)\left(y-y_{i}\right)\right]^{2}\right\}^{-2}+\operatorname{cov}(u, w), \quad \text { A } 5 \\
\sigma_{v}{ }^{2}= & \left\langle\sum \sigma _ { v i } { } ^ { 2 } \left\{ R_{i}\left(y-y_{i}\right) \sum\left(x-x_{i}\right)^{2}-R_{i}\left(x-x_{i}\right)\right.\right. \\
& \left.\times\left[\sum\left(x-x_{i}\right)\left(y-y_{i}\right)\right]\right\}^{2}+\sigma_{w}{ }^{2}\left[\sum\left(x-x_{i}\right)^{2}\right.
\end{aligned}
$$

$$
\begin{aligned}
& \times \sum\left(y-y_{i}\right)\left(z-z_{i}\right)-\sum\left(x-x_{i}\right)\left(y-y_{i}\right) \\
& \left.\left.\times \sum\left(x-x_{i}\right)\left(z-z_{i}\right)\right]^{2}\right\rangle \\
& \times\left\{\sum\left(x-x_{i}\right)^{2} \sum\left(y-y_{i}\right)^{2}\right. \\
& \left.\quad-\left[\sum\left(x-x_{i}\right)\left(y-y_{i}\right)\right]^{2}\right\}^{-2}+\operatorname{cov}(v, w),
\end{aligned}
$$

where

$$
\sigma_{W}^{2}=\sigma_{w}^{2}+\sigma_{v t}^{2} .
$$

For downward integration where $\kappa$ is an index denoting height level, derivatives have been approximated by centered differences, and the integration approximated through the trapezoidal rule. The $\sigma_{v t}{ }^{2}$ is the variance of the fall speed estimate. In storm regions containing large hail, incorrect assignment of the proper hail terminal velocity can dominate the $\sigma_{v t}{ }^{2}$ error term.

\section{Direct method}

If three or more observations are made at a point from at least the distinctly different viewing angles, it is possible to find the vertical particle motion directly. The vertical wind is found by removing the fall speed contribution. The uncertainty in the vertical particle motion is expressed

$$
\begin{aligned}
\sigma_{w}{ }^{2}=\sum \sigma_{v i}{ }^{2}\left[B_{13}\left(x-x_{i}\right) R_{i}\right. & +B_{23}\left(y-y_{i}\right) R_{i} \\
& \left.+B_{33}\left(z-z_{i}\right) R_{i}\right]^{2}
\end{aligned}
$$

where the $B_{i j}$ in the equation are elements of the inverse of the coefficient matrix [C] coefficients:

$$
\left[\begin{array}{lll}
\sum\left(x-x_{i}\right)^{2} & \sum\left(x-x_{i}\right)\left(y-y_{i}\right) & \sum\left(x-x_{i}\right)\left(z-z_{i}\right) \\
\sum\left(x-x_{i}\right)\left(y-y_{i}\right) & \sum\left(y-y_{i}\right)^{2} & \sum\left(y-y_{i}\right)\left(z-z_{i}\right) \\
\sum\left(x-x_{i}\right)\left(z-z_{i}\right) & \sum\left(y-y_{i}\right)\left(z-z_{i}\right) & \sum\left(z-z_{i}\right)^{2}
\end{array}\right]\left[\begin{array}{c}
u \\
v \\
W
\end{array}\right]=\left[\begin{array}{l}
\sum V_{i}\left(x-x_{i}\right) R_{i} \\
\sum V_{i}\left(y-y_{i}\right) R_{i} \\
\sum V_{i}\left(z-z_{i}\right) R_{i}
\end{array}\right] .
$$

The error in $\sigma_{w}{ }^{2}$ will be unbounded at flight level since no component of the vertical wind is observed when the antenna points horizontally.

To overcome the limitations presented in the solution to (A8), variations on the direct method can be employed. For example, the horizontal wind components can be computed with the companion equation to (A5). The horizontal wind field is not contaminated by uncertainties in $V_{i}$. Then the vertical component may be obtained from the equation of continuity.

\section{REFERENCES}

Cunning, J. C., 1987: The Oklahoma-Kansas preliminary regional experiment for STORM-Central. Bull. Amer. Meteor. Soc., 67, 1478-1486.

Frush, C., P. Hildebrand and C. Walther, 1986: The NCAR airborne Doppler radar Part II: System design considerations. Preprints 23 Conf. Radar Meteorology. Snowmass, Amer. Meteor. Soc., 151-154.

Hildebrand, P. H., and C. K. Mueller, 1985: Evaluation of meteorological airborne radar. Part I: Dual-Doppler analyses of air motions. J. Atmos. Oceanic Technol., 2, 362-380.

_- C. C. Walther, C. Frush and C. Mueller, 1983: Airborne Doppler weather radar: Evaluation and discussion of applications. Preprints 21 st Conf. Radar Meteorology. Edmonton, Amer. Meteor. Soc., 270-277.
Jorgensen, D. P., and F. D. Marks, Jr., 1984: Airborne Doppler radar study of the structure and three-dimensional airflow within a hurricane rainband. Preprints, 22nd Conf. Radar Meteorology. Zurich, Amer. Meteor. Soc., 572-577.

- , P. H. Hildebrand and C. L. Frush, 1983: Feasibility test of an airborne pulse-Doppler meteorological radar. J. Climate Appl. Meteor, 22, 744-757.

Mueller, C. K., and P. H. Hildebrand, 1985: Evaluation of meteorological airborne radar. Part II: Triple-Doppler analyses of air motions. J. Atmos. Oceanic Technol., 2, 381-392.

Ray, P. S., and K. L. Sangren, 1983: On multiple-Doppler radar network design. J. Climate Appl. Meteor., 22, 1444-1453.

bining airborne and ground-based Doppler radar data. Preprints 23rd Conf. Radar Meteorology, Snowmass, Amer. Meteor. Soc., 139-142.

—, C. L. Ziegler, W. Bumgarner and R. J. Serafin, 1980: Single and multiple-Doppler radar observations of tornadic storms. Mon. Wea. Rev., 108, 1607-1625.

—, D. P. Jorgensen and Sue-Lee Wang, 1985: Airborne Doppler radar observations of a convective storm. J. Climate Appl. Meteor., 24, 688-698.

Walther, C., C. Frush and P. Hildebrand, 1986: The NCAR airborne Doppler radar Part III: Overview of radar design details. Preprints 23 Conf. Radar Meteorology. Snowmass, Amer. Meteor. Soc., 155-158. 